\title{
Validity and reliability of the short version of the Problematic Pornography Consumption Scale (PPCS-6- A) in adolescents.
}

Bőthe, Beáta; Vaillancourt-Morel, Marie-Pier; Dion, Jacinthe; Štulhofer, Aleksandar; Bergeron, Sophie

Source / Izvornik: Psychology of Addictive Behaviors, 2021, 35, 486 - 500

Journal article, Accepted version

Rad u časopisu, Završna verzija rukopisa prihvaćena za objavljivanje (postprint)

https://doi.org/10.1037/adb0000722

Permanent link / Trajna poveznica: https://urn.nsk.hr/urn:nbn:hr:131:050968

Rights / Prava: In copyright/Zaštićeno autorskim pravom.

Download date / Datum preuzimanja: 2023-04-26

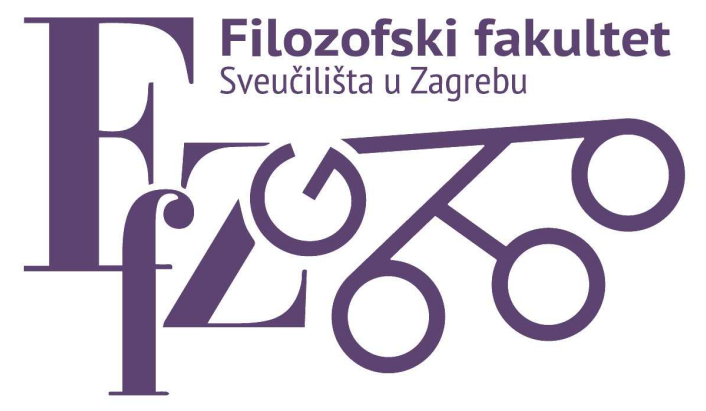

Repository / Repozitorij:

ODRAZ - open repository of the University of Zagreb Faculty of Humanities and Social Sciences
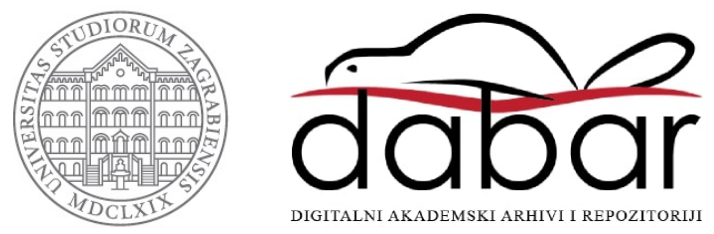


\section{Validity and Reliability of the Short Version of the Problematic Pornography Consumption \\ Scale (PPCS-6-A) in Adolescents}

Beáta Bőthe, $\mathrm{PhD}^{1 *}$, Marie-Pier Vaillancourt-Morel, $\mathrm{PhD}^{2}$, Jacinthe Dion, $\mathrm{PhD}^{3}$, Aleksandar Štulhofer, $\mathrm{PhD}^{4}$, Sophie Bergeron, $\mathrm{PhD}^{1}$

${ }^{1}$ Département de Psychologie, Université de Montréal, Montréal, Canada

${ }^{2}$ Département de Psychologie, Université du Québec à Trois-Rivières, Trois-Rivières, Canada

${ }^{3}$ Intersectoral Center for Sustainable Health, Université du Québec à Chicoutimi, Chicoutimi, Canada

${ }^{4}$ Department of Sociology, Faculty of Humanities and Social Sciences, University of Zagreb, Zagreb, Croatia

*Corresponding author

Beáta Bőthe, Ph.D., Department of Psychology, Université de Montréal, C.P. 6128, Succursale Centre-Ville, Montréal, QC, H3C 3J7, Canada

E-mail: beata.bothe@umontreal.ca; beabothe@gmail.com

Tel.: + 514-343-6111 ext. 37428

This document is a pre-publication version of the following manuscript:

Bőthe, B., Vaillancourt-Morel, M-P., Dion, J., Štulhofer, A., \& Bergeron, S. (accepted). Validity and reliability of the short version of the Problematic Pornography Consumption Scale (PPCS-6A) in adolescents. Psychology of Addictive Behaviors.

C 2021. This paper is not the copy of record and may not exactly replicate the final, authoritative version of the article published in Psychology of Addictive Behaviors. The final authenticated version will be available online on the publisher's website. 
Funding: This work was supported by the Merit Scholarship Program for Foreign Students (PBEEE) awarded by the Ministère de l'Éducation et de l'Enseignement Supérieur (MEES) to B.

Böthe, and a grant from the Canadian Institutes of Health Research awarded to S. Bergeron and J. Dion.

Acknowledgements: The authors thank Mylène Desrosiers, Catherine Clouston, and Camélia Dubois for their assistance with data collection.

Conflict of Interest: The authors declare that they have no conflict of interest.

\section{Author Contributions:}

Conception and design: Beáta Bőthe, Marie-Pier Vaillancourt-Morel, Jacinthe Dion, Sophie Bergeron

Analysis of data: Beáta Böthe

Interpretation of data: Beáta Bőthe, Marie-Pier Vaillancourt-Morel, Jacinthe Dion, Aleksandar Štulhofer, Sophie Bergeron

Drafting the article: Beáta Bőthe

Revising it critically for important intellectual content: Marie-Pier Vaillancourt-Morel, Jacinthe Dion, Aleksandar Štulhofer, Sophie Bergeron

Final approval of the version to be published: Beáta Bőthe, Marie-Pier Vaillancourt-Morel, Jacinthe Dion, Aleksandar Štulhofer, Sophie Bergeron 


\title{
Validity and Reliability of the Short Version of the Problematic Pornography Consumption Scale (PPCS-6-A) in Adolescents
}

\begin{abstract}
Objective: Despite the high prevalence of adolescents' pornography use and increasing societal concerns about it, the examination of problematic pornography use (PPU) among this population is still scarce, potentially due to the lack of well-validated, reliable measures. The aims of the present study were to validate a short, theory-based measure of PPU in a diverse sample of adolescents and identify a potentially at-risk problematic pornography user group. Method: We used a sample of 802 adolescents (35\% girls; $14 \%$ sexual minority; $M_{a g e=15.4}$ years, $S D=0.6$ ) who reported lifetime pornography use, collected as part of an ongoing longitudinal study on adolescents' sexual health. To examine the psychometric properties of the short, sixitem version of the Problematic Pornography Consumption Scale for adolescents (PPCS-6-A), we conducted confirmatory factor analysis, gender and sexual orientation measurement invariance testing, and assessed theoretically relevant correlates (e.g., masturbation frequency). We conducted latent profile analysis to identify adolescents at risk of PPU.

Results: The PPCS-6-A demonstrated strong psychometric properties in terms of factor structure, measurement invariance (i.e., boys vs. girls, and heterosexual vs. sexual minority adolescents), and reliability, and correlated reasonably with the assessed variables. Ten percent of participants were identified as being at-risk of PPU.

Conclusions: The PPCS-6-A can be considered a short, reliable, and valid scale to assess PPU in adolescents, and may distinguish between low-risk and at-risk problematic users. Its use in future studies could lead to a better understanding of the prevalence and characteristics of adolescents' PPU.
\end{abstract}


Keywords: pornography; problematic pornography use; Problematic Pornography Consumption

Scale (PPCS); PPCS-6; screening

\section{Public Health Significance Statements}

- This study demonstrated that the short version of the Problematic Pornography Consumption Scale is a valid and reliable measure of problematic pornography use in adolescents, including boys, girls, heterosexual and sexual minority adolescents.

- Ten percent of participants were identified as potentially at-risk problematic pornography users, indicating that a small but still significant group of adolescents may experience that their pornography use is uncontrollable and results in significant distress and functional impairment in their lives. 


\section{Validity and Reliability of the Short Version of the Problematic Pornography Consumption Scale (PPCS-6-A) in Adolescents}

Since the availability of easy internet access and technological advancements in industrialized countries, pornography use has become more prevalent than ever before. Based on objective website traffic data, pornography use increased by $310 \%$ between 2004 and 2016, being the most popular among adolescents and young adults (Lewczuk et al., 2019). There are increasing societal concerns about adolescents' pornography use (Keen et al., 2020), especially when considering that pornography may represent youth's first contact with sexuality, playing an important role in their sexual development (Peter \& Valkenburg, 2016). However, the examination of adolescents' problematic pornography use (PPU) - defined as persistent patterns of uncontrollable use despite significant distress and functional impairment (Bőthe, Tóth-Király, et al., 2020; Kraus et al., 2018) - is still scarce in the literature (Kohut \& Štulhofer, 2018;

Štulhofer et al., 2020). One potential obstacle to moving this area forward is the lack of wellvalidated measures of PPU in this population. The aims of the present study were to validate a short, theory-based measure of PPU in a diverse sample of adolescents and identify a potentially at-risk problematic pornography user group.

\section{Adolescents' Pornography Use}

Prevalence rates of adolescents' pornography use vary widely from one study to another due to conceptual and methodological shortcomings, such as examining nationally representative vs. convenience samples or assessing intentional vs. unintentional pornography use (Peter \& Valkenburg, 2016). Nevertheless, based on data from nationally representative adolescent studies from the US and Europe (Lobe et al., 2011; Wolak et al., 2007), 23\% to 42\% of adolescents (aged between 9 to 17 years) reported past-year pornography use. According to previous studies (Böthe, Vaillancourt-Morel, et al., 2020; Peter \& Valkenburg, 2016; Sinković et al., 2013), teenagers tend 
to have their first experience with pornography in early adolescence (i.e., around the age of 12), with one-third of them having their first experience before the age of 11 and more than 50\% reporting using it weekly or more often.

A high ratio of adolescents in industrialized countries report viewing pornography (Böthe, Vaillancourt-Morel, et al., 2020; Lobe et al., 2011; Wolak et al., 2007), and most of them appear to use it frequently without reporting any negative impact on their life (Efrati, 2020; Kohut \& Štulhofer, 2018; Štulhofer et al., 2020). However, there is a smaller but still significant number of adolescents whose pornography use may become problematic (Doornwaard et al., 2016; Efrati, 2020; Efrati \& Gola, 2018; Kohut \& Štulhofer, 2018; Štulhofer et al., 2020), and may result in negative consequences over time, such as higher levels of psychological distress and sexual problems (Grubbs et al., 2015; Grubbs \& Gola, 2019). In particular, 5\% to 14\% of 14 to 19-yearold adolescents reported excessive, compulsive, or problematic use of pornography (Efrati \& Gola, 2018; Pizzol et al., 2016; Štulhofer et al., 2020; Svedin et al., 2011). When problematic cybersex use (including pornography use) was assessed among 15 to 18 -year-old adolescents, $6 \%$ to $19 \%$ of girls and $18 \%$ to $38 \%$ of boys were identified as at-risk cybersex users (i.e., excessive cybersex use), and $1 \%$ of girls and $0 \%$ to $1 \%$ of boys were identified as pathological cybersex users (i.e., compulsive, out-of-control cybersex use), based on cut-off scores validated with adult users (Ballester-Arnal et al., 2017).

Although the aforementioned studies showed some important preliminary findings that suggest pornography use might be problematic for some adolescents, several limitations should be considered and might explain the broad range of PPU estimates in adolescents. First, most studies examining PPU were conducted exclusively among adolescent boys (Doornwaard et al., 2016; Kohut \& Štulhofer, 2018; Pizzol et al., 2016; Rousseau et al., 2020; Štulhofer et al., 2020; Svedin et al., 2011), limiting the generalizability of the findings to girls. Second, most prior 
studies assessed broader concepts such as cybersex use or compulsive sexual behaviors in general (Ballester-Arnal et al., 2017; Efrati \& Dannon, 2019; Efrati \& Gola, 2018), precluding the accurate examination of PPU. Finally, prior studies examining PPU among adolescents either only assessed the frequency of adolescents' pornography use and considered frequent use as problematic (Cho, 2016; Svedin et al., 2011) or used scales that were developed and validated with adult populations (Doornwaard et al., 2016; Kohut \& Štulhofer, 2018; Morelli et al., 2017), without a careful examination of the psychometric properties of the scales in adolescent samples. Thus, a necessary next step is to validate a scale assessing PPU among adolescents, laying the foundation for future research on PPU in this population. Given adolescence provides the ideal window to identify and modify emerging problematic behaviors before they crystallize in adulthood, this step has critical implications for both youth and adults' sexual health.

\section{Assessment of Problematic Pornography Use}

Despite the inclusion of Compulsive Sexual Behavior Disorder (CSBD) in the 11th edition of the International Statistical Classification of Diseases and Related Health Problems (ICD-11, World Health Organization, 2019), it cannot be conclusively determined whether CSBD should be considered as an impulse control, compulsivity-related, or addictive disorder (Kor et al., 2013; Kraus et al., 2016; Potenza et al., 2017; Prause et al., 2017; Sassover \& Weinstein, 2020). Similarly, there is no consensus in the literature about the conceptualization of PPU (Bőthe, Tóth-Király, et al., 2019; Ley et al., 2014). Nevertheless, PPU is often considered as a manifestation or subcategory of CSBD (Fernandez \& Griffiths, 2019; Kafka, 2010); thus, it may be defined as persistent, repetitive patterns of uncontrollable pornography use despite significant personal distress and functional impairment in different life domains (Kraus et al., 2018). To date, more than 20 scales were developed to examine PPU among adults, but no scale assessing PPU has been rigorously validated in adolescent populations (Fernandez \& Griffiths, 
2019). These scales relied on different theoretical conceptualizations (e.g., addiction or compulsivity framework) and demonstrated varying psychometric properties (e.g., some scales demonstrated strong reliability and validity, whereas others showed weaker validity as they only focused on some components of PPU but not others).

Based on the findings of recent systematic literature reviews (Fernandez \& Griffiths, 2019; Grubbs et al., 2020), the Problematic Pornography Consumption Scale (PPCS and PPCS-6, Bőthe, Tóth-Király, Demetrovics, et al., 2020; Bőthe, Tóth-Király, et al., 2018) is one of the most psychometrically robust to assess PPU. The other two scales recommended for use are the Problematic Pornography Use Scale (PPUS, Kor et al., 2014) and the Brief Pornography Screen (BPS, Kraus et al., 2020). However, both the PPUS and the BPS have some limitations compared to the PPCS and the PPCS-6. For example, the PPCS-6 includes six short and easily understandable items, whereas the PPUS includes 12 items and some of the items are quite long. Thus, the PPUS may be more difficult to understand for adolescents than the PPCS-6. The BPS is a promising new scale to assess dysregulated pornography use, but its psychometric properties have not been examined as thoroughly as those of the PPCS. The PPCS demonstrated strong psychometric properties in terms of construct, convergent, divergent, and clinical validity and utility (Bőthe et al., 2017; Bőthe, Tóth-Király, et al., 2018, 2019; Bőthe, Koós, et al., 2019; Bőthe, Lonza, Štulhofer, et al., 2020; Bőthe, Tóth-Király, Bella, et al., 2020; Bőthe, Tóth-Király, Demetrovics, et al., 2020; Bőthe et al., 2021; Tóth-Király et al., 2019).

Moreover, gender, sexual orientation, treatment-seeking status, and culture-based measurement invariance have been established for the PPCS in previous studies (Bőthe, TóthKirály, Demetrovics, et al., 2020; Bőthe, Tóth-Király, et al., 2018; Chen et al., 2021), while no measurement invariance has been tested for the BPS yet, and only some preliminary results are available for the PPUS (Borgogna et al., 2018, 2019). In addition, a large-scale mixed-method 
study including quantitative analyses, clinical interviews with patients reporting PPU, and therapists' clinical assessments, demonstrated that all PPU symptoms assessed by the PPCS were endorsed by both patients and therapists, and concluded that the PPCS is a more accurate, reliable, and valid measure than other PPU scales (Chen \& Jiang, 2020). Lastly, the PPCS is the only instrument that explicitly assesses tolerance (i.e., an important component of potentially addictive behaviors, Griffiths, 2005) and has a reliable cut-off score that distinguishes between problematic and non-problematic adult users (Bőthe, Tóth-Király, et al., 2018; Bőthe, TóthKirály, Demetrovics, et al., 2020).

The PPCS assesses PPU through six dimensions based on Griffiths' six-component model of addiction (Griffiths, 2005). Salience refers to the importance of pornography use in one's life. Tolerance describes the process of gradual increase in pornography use to reach satisfaction. Mood modification refers to the act when one turns to pornography to reduce negative feelings and emotions. Conflict describes intra- and interpersonal problems related to one's pornography use. Withdrawal captures psychological distress and/or withdrawal symptoms appearing in the absence of pornography use. Finally, relapse describes one's unsuccessful efforts to reduce or stop pornography use. Pornography use is considered problematic only if an individual demonstrates all symptoms of PPU, as an individual may report some of these characteristics without problematic use, for example, due to high but nonproblematic engagement (Billieux et al., 2019; Bőthe, Lonza, Štulhofer, et al., 2020; Tóth-Király et al., 2018), or moral incongruence concerning pornography use (Grubbs, Perry, et al., 2019; Grubbs \& Perry, 2019). In sum, the PPCS is a robust scale grounded in a solid theoretical background and demonstrating strong psychometric properties in diverse adult populations. It is thus an appropriate basis for examining PPU among adolescents.

\section{Differences Based on Gender and Sexual Orientation in Adolescents' Pornography Use}


Significant gender and sexual orientation-based differences may be observed regarding adolescents' pornography use (Böthe, Vaillancourt-Morel, Bergeron, et al., 2019). Based on prior large-scale studies (Bőthe, Vaillancourt-Morel, Girouard, et al., 2020; Sinković et al., 2013), boys use pornography from a younger age than girls, as boys reported first exposure around the age of 11.5 years, whereas girls reported it to be around the ages of 12 to 13.5 years. Also, based on the results of a recent study involving more than 2800 adolescents, boys reported weekly or more frequent pornography use, whereas girls reported monthly or less frequent pornography use (Bőthe, Vaillancourt-Morel, Girouard, et al., 2020).

Moreover, sexual and gender minority adolescents, particularly sexual and gender minority girls, may also use pornography from a younger age (Bőthe, Vaillancourt-Morel, et al., 2019; Böthe, Vaillancourt-Morel, Girouard, et al., 2020). Sexual and gender minority girls reported their first pornography use half a year earlier than heterosexual, cisgender girls on average (12.3 years and 12.9 years, respectively) (Bőthe, Vaillancourt-Morel, Girouard, et al., 2020). Sexual and gender minority adolescents may use pornography more frequently than their heterosexual, cisgender peers due to sexuality and sexual identity-related information seeking, but this difference might not be as pronounced as differences between boys and girls (Böthe, Vaillancourt-Morel, et al., 2019; Bőthe, Vaillancourt-Morel, Girouard, et al., 2020). However, to conclude with confidence that observed gender or sexual orientation-related differences in adolescents' pornography use are meaningful, it is critical to first establish the measurement invariance (or lack of invariance) of scales as a function of these characteristics (Millsap, 2011).

\section{Aims of the Present Study}

The aim of the present study was to validate the short version of the Problematic Pornography Consumption Scale (adapted to adolescents, PPCS-6-A) in a large, diverse sample of adolescents. First, we examined the factor structure (i.e., confirmatory factor analysis) and 
reliability of the scale. Next, we conducted measurement invariance testing to examine whether the PPCS-6-A functions the same way in gender- and sexual orientation-based subgroups. Given PPU's theoretically relevant and empirically pre-established positive associations with pornography use and masturbation frequency (Böthe, Tóth-Király, Demetrovics, et al., 2020; Grubbs, Perry, et al., 2019; Kohut \& Štulhofer, 2018), age at first pornography use (Gola et al., 2016; Lewczuk et al., 2017), sexual interest and arousal, and sexual distress (Bőthe et al., 2021; Leonhardt et al., 2020; Wéry \& Billieux, 2016), we assessed these constructs as correlates to examine the convergent validity of PPCS-6-A. Lastly, similarly to prior work in adults and adolescent boys (Bőthe, Tóth-Király, et al., 2018; Štulhofer et al., 2020), latent profile analysis was conducted to identify adolescents potentially at risk of PPU.

\section{Method}

\section{Participants}

A total of 802 participants $\left(M_{a g e}=15.41\right.$ years, $\left.S D=0.57\right)$ were included in the present study. Concerning participants' gender, 517 (64.5\%) were a boy, 281 were a girl (35.0\%), three $(0.4 \%)$ non-binary, gender fluid or something else (e.g., genderqueer), and one $(0.1 \%)$ selected the "other" answer option. The majority of adolescents $(65.3 \% ; n=524)$ were French Canadian, 11.8\% $(n=95)$ English Canadian, 3.5\% $(n=28)$ African, 3.0\% $(n=24)$ Latin or South American, 3.0\% $(n=24)$ European, and 13.4\% $(n=107)$ reported other cultural identities. As for sexual orientation, $688(85.8 \%)$ adolescents were heterosexual, $26(3.2 \%)$ were questioning their sexual orientation, $11(1.4 \%)$ were homosexual, $10(1.2 \%)$, heteroflexible, one $(0.1 \%)$, homoflexible, $30(3.7 \%)$, bisexual, one $(0.1 \%)$, queer, $10(1.2 \%)$, pansexual, $21(2.6 \%)$ chose the "none of the above" answer option, and four $(0.5 \%)$ did not want to answer this question.

\section{Procedure}


Data were collected during the second wave of an ongoing bi-center Canadian longitudinal study on adolescents' sexual health that began in 2018. Ensuring sample diversity, we recruited participants from large metropolitan and rural areas and schools in the province of Québec. Schools serving students from different socioeconomic backgrounds and Caucasian and multi-ethnic populations were approached. Participants completed a self-report, anonymous survey, using a secure online platform (Qualtrics Research Suite) in their classrooms on tablets provided by research assistants, ensuring greater confidentiality. Students clicked a secure and confidential link, received detailed information about the aims of the study, and provided informed consent prior to beginning completion of the measures. In Québec (Canada), adolescents can provide their own informed consent from the age of 14 . Not relying on parental consent can ensure the safety of students involved in the study, and can prevent sampling biases that may distort the results. Informed consent did not require a signature or the student's name, further ensuring complete anonymity. Students who did not want to participate in the study could complete another activity put on the tablet by our team, such that other students could not tell who was completing our measures or who was doing the other activity. We used a secret code as an anonymous identifier. To generate their unique identification code, students answered eight questions (e.g., the first letter of your mother's or female caregiver's first name, the first letter of the city where they were born). Survey completion took 30 to 45 minutes. The survey included three attention-testing questions. If students failed at least two out of these questions, their data were considered invalid (Thomas \& Clifford, 2017). Study participation was compensated with a $10 \$$ gift card.

Specifically, these Wave 2 data were collected between November 2019 and February 2020, prior to the occurrence of COVID-19. Overall, 1,175 students attending tenth grade were approached, and a participation rate of $99.15 \%$ was reached (only ten students refused to 
participate). Students could participate in the study if they were in tenth grade and at least 14 years old. Out of the 1,165 adolescents who agreed to participate, 30 participants were excluded because they failed at least two out of the three attention-testing questions. Only participants who had ever viewed pornography in their lifetime were included in the present study. This resulted in a final sample of 802 participants $(70.7 \%)$. The research procedure was approved by the two research centers' Institutional Review Boards and was carried out under the Declaration of Helsinki.

\section{Measures}

Gender and Sexual Orientation. Adolescents' gender identity was assessed with the following question based on prior recommendations (Bauer et al., 2017): “What gender or gender identity do you identify with?", answer options were: masculine/man; feminine/woman; indigenous or other cultural gender minority identity (e.g., two-spirit); non-binary, gender fluid or something else (e.g., genderqueer); and other (with specification). Adolescents's sexual orientation was assessed with the following item based on prior recommendations (Weinrich, 2014): "People describe their sexual orientation in different ways. Which expression best describes your current sexual orientation? If no expression describes you, check "None of the above" and write the answer that describes you personally."; answer options were: straight; I do not know yet, or I am currently questioning my sexual orientation; gay or lesbian or homosexual; heteroflexible; homoflexible; bisexual; queer; pansexual; asexual; none of the above; I don't want to answer; other (with specification). To simplify the statistical analysis and increase statistical power, we created two groups based on gender and sexual orientation. In the case of gender, those who reported being a boy $(n=517)$ were included in the boys' group, whereas those who reported being a girl $(n=281)$ were included in the girls' group. Given that only three adolescents reported being non-binary, gender fluid or something else (e.g., genderqueer), and 
one $(0.1 \%)$ selected the "other" answer option, we could not compare their group to the boys' and girls' groups statistically, but descriptive statistics are provided for them as well. In the case of sexual orientation, the heterosexual group included participants who were heterosexual $(n=$ 688). The sexual minority group included participants who were questioning their sexual orientation; were gay or lesbian; heteroflexible; homoflexible; bisexual; queer; pansexual; or chose the "none of the above" option $(n=110)$.

Pornography Use. Before answering any pornography-related questions, participants were provided the following definition (Kohut et al., 2018): "For the following questions, the term 'pornography' is used to refer to: intentionally looking at or listening to: (1) pictures or videos of nude individuals, (2) pictures or videos in which people are having sexual activities". Participants answered three pornography-related questions. First, participants answered one question about their lifetime pornography use ("Have you ever watched pornography in your life?"; $0=n o ; 1=y e s$ ). If they had viewed pornography in their lifetime, they were asked to report their age at first use ("How old were you the first time you watched pornography?"), and frequency of use in the past three months ("On average in the last three months, how many times did you watch pornography?") on an eight-point scale $(0=$ never; $7=$ many times per day $)$ (Bőthe, Vaillancourt-Morel, Girouard, et al., 2020; Kohut et al., 2018).

Problematic Pornography Consumption Scale-Short Version (PPCS-6). The short version of the PPCS-6 (Bőthe, Tóth-Király, Demetrovics, et al., 2020) assesses PPU with six items, each item representing one component of Griffiths' six-component model of addiction (Bőthe, Tóth-Király, et al., 2018; Griffiths, 2005): salience, tolerance, mood modification, relapse, withdrawal, and conflict. Following prior guidelines (Haynes et al., 1995; Marsh, Ellis, et al., 2005; Orosz et al., 2016, 2018), the items of the PPCS-6 were selected based on theoretical and empirical considerations by independent evaluations of experts in the field of clinical 
psychology and addiction, pornography research, and scale validation. All items of the original scale (PPCS, Böthe, Tóth-Király, et al., 2018) were evaluated based on the adequacy of corrected item-total correlations, standardized factor loadings, skewness, and kurtosis values, and covering the breadth of the given component. The original PPCS and the PPCS-6 had positive, strong associations ( $r$ s ranging between .96 to .97 ) in three independent samples, including treatmentseeking individuals (Bőthe, Tóth-Király, Demetrovics, et al., 2020). The PPCS-6 was adapted to adolescent populations in the present study (PPCS-6-A; Appendix A) ${ }^{1}$. Participants indicated their answers on a seven-point scale $(1=$ never; $7=$ all the time $)$ regarding the past six months. Higher scores indicate higher levels of PPU.

Masturbation. Before answering any masturbation-related questions, participants were provided the following definition: "For the following questions, "masturbation" refers to seeking sexual pleasure by self-stimulation of the genitals (i.e., by oneself), either by manual caresses, sex toys, rubbing, pressure or any other technique. Masturbation may or may not lead to an orgasm.". First, participants answered one question about lifetime masturbation ("Do you masturbate?"; $0=n o ; 1=$ yes). If they had masturbated, they were asked to report the frequency of masturbation in the past three months ("On average, over the past three months, how often did you masturbate?") on an eight-point scale (1 = not once in the past three months; $8=$ more than once a day). Based on the responses to the lifetime masturbation and frequency of masturbation variables, we computed a new masturbation frequency variable. We recoded the responses of those adolescents who indicated that they had not masturbated previously (i.e., answering "no" to

\footnotetext{
${ }^{1}$ The scale was adapted to the adolescent population by experts in the field of clinical psychology, addiction, and sex research among adolescents. The instruction of the scale and the items were carefully revised and modified by the experts to be easier to understand for adolescents. For example, shorter synonyms were used when appropriate (e.g., Item 3 in the original scale included the expression "leisure activities", but it was changed to "fun activities" in the present version of the scale). Despite these modifications, the meaning of the items did not change, and thus, they still represent the original six components of the PPCS-6 (Bőthe, Tóth-Király, Demetrovics, et al., 2020).
} 
the lifetime masturbation question) to represent "never" in the masturbation frequency question. We used this new masturbation frequency variable in further analyses.

Sexual Interest and Arousal. Participants answered one question about their sexual thoughts ("During the last month, how often did you have sexual thoughts?") in the past month adapted from the Sexual Desire Inventory-2 (Spector et al., 1996). They indicated their response on a seven-point scale $(1=$ not at all; $7=a$ lot $)$. Moreover, they answered one question about their sexual drive ("How strong is your sex drive?", answer options: $1=$ extremely strong; $6=$ no sex drive) and one question about their levels of sexual arousal ("How easily are you sexually aroused (turned on)?", answer options: $1=$ extremely easily, $6=$ never aroused), based on the Arizona Sexual Experience Scale (McGahuey et al., 2000). These two items were recoded so that higher scores reflect higher levels of sexual drive and sexual arousal.

Sexual Distress. Participants completed the short, adapted version of the Sexual Distress Scale (SDS, Derogatis et al., 2002; Pâquet et al., 2018). The SDS assesses how often a sexual difficulty caused distress in one's life with three items (e.g., "How often did you feel distressed about your sex life?"). Participants indicated their answers on a five-point scale $(0=$ never; $4=$ always) regarding the past month. Higher scores indicate higher levels of sexual distress. The scale demonstrated adequate reliability in the present study $(\alpha=.75)$.

\section{Statistical Analyses}

We computed descriptive statistics and correlations in SPSS 25. Correlations around |.10| were considered weak, |.30| moderate, and |.50| strong (Cohen, 1992). We used Mplus 7.3 for multivariate analyses. First, we conducted confirmatory factor analysis (CFA) to examine the structural validity of the PPCS-6-A using the weighted least squares mean- and variance-adjusted estimator (WLSMV), which has been found to be superior to maximum-likelihood estimation for ordered-categorical items, particularly when the response categories follow asymmetric 
thresholds (for a review, see Finney \& DiStefano, 2013). Models were evaluated with commonly used goodness-of-fit indices (Browne \& Cudeck, 1993; Marsh, Hau, et al., 2005; SchermellehEngel et al., 2003): Comparative Fit Index (CFI; $\geq .90$ adequate; $\geq .95$ good), Tucker-Lewis index (TLI; $\geq .90$ adequate; $\geq .95$ good), and Root-Mean-Square Error of Approximation with its 90\% confidence interval (RMSEA; $\leq .08$ adequate, $\leq .05$ good, Schermelleh-Engel et al., 2003; and $.10 \leq$ may be acceptable, Browne \& Cudeck, 1993, Kenny et al., 2015). However, RMSEA values need to be evaluated in light of the sample size, degrees of freedom, and model specification in each study, and multiple fit indices should be evaluated simultaneously when deciding about a model's adequacy (Chen et al., 2008; Kenny et al., 2015). Cronbach's alpha ( $\geq$ .70 acceptable) and composite reliability $(\mathrm{CR} ;>.50$ acceptable) were used to assess the reliability (Nunnally, 1978; Perreira et al., 2018; Raykov, 1997).

To ensure that gender- and sexual orientation-based comparisons are meaningful and reduce the possibility of measurement biases and invalid comparisons between groups (Böthe, Bartók, et al., 2018; Millsap, 2011; Vandenberg \& Lance, 2000), we conducted tests of measurement invariance using participants' gender (boys vs. girls) and sexual orientation (heterosexual vs. sexual minority) as grouping variables in separate analyses. In each analysis, we tested and compared six levels of invariance with increasingly constrained parameters: configural, metric, scalar, residual, latent variance, and latent mean invariance. It is important to note that the first four steps examine the presence of potential measurement biases and differences (i.e., measurement invariance in a narrower sense), the last two steps examine the presence of group-based differences on the level of variance and means (i.e., structural invariance). Testing the last two steps of invariance is optional; however, it provides valuable information about differences in (latent) levels of PPU between the examined groups (Milfont \& Fischer, 2010; Vandenberg \& Lance, 2000). Significant decreases in CFI ( $\Delta \mathrm{CFI} \leq .010)$ and 
increases in RMSEA $(\triangle \mathrm{RMSEA} \leq .015)$ suggested which level of measurement invariance was achieved (Chen, 2007; Cheung \& Rensvold, 2002). Moreover, it is suggested to report additional fit indices $(\Delta \mathrm{TLI})$, as they may incorporate control for parsimony, and thus may be advantageous in model comparisons (Marsh et al., 2013; Marsh, Hau, et al., 2005).

To examine the convergent validity of the PPCS-6-A, we assessed associations with theoretically relevant correlates. We examined the correlations separately for boys and girls, and heterosexual and sexual minority participants to corroborate the findings in each group.

To identify potentially at-risk problematic pornography users, we conducted latent profile analysis (LPA) with the robust maximum likelihood estimator (Collins \& Lanza, 2010), based on the items of the PPCS-6-A. We estimated models, including one to four classes. The selection of the optimal number of classes was guided by the theoretical meaningfulness and statistical adequacy (e.g., the absence of negative variance estimates) of the extracted classes (Marsh et al., 2009). We used the following indices to determine the number of latent classes: Akaike Information Criterion (AIC), bias-corrected Akaike Information Criterion (CAIC), Bayesian Information Criterion (BIC), and Sample-Size Adjusted Bayesian Information Criterion (SSABIC). Lower values indicate more parsimonious and better fitting models. We reported the model entropy, providing information about classification accuracy, although it should not be directly used to guide the selection of the optimal solution (Lubke \& Muthén, 2007). We also reported the Lo-Mendell-Rubin Adjusted Likelihood Ratio Test (aLMR Test), whereby a nonsignificant value suggests the superiority of a model with one less class. Once the final solution was identified, we compared the classes on the basis of the correlates using Mplus' (e) auxiliary function (Asparouhov \& Muthén, 2007), testing the equality of the means of the correlates across the classes without assuming directionality between class membership and the correlates.

\section{Results}




\section{Structural Validity and Reliability of the PPCS-6-A}

Given that the PPCS-6-A is a theory-based scale (Griffiths, 2005) and demonstrated good psychometric properties using a one-factor model in previous studies (Bőthe, Tóth-Király, Demetrovics, et al., 2020) and a one-factor solution emerged based on the results of an exploratory factor analysis in the present study, we conducted a CFA to examine the adequacy of the one-factor model (Table 1). Although the RMSEA value was greater than .08 , the CFI and TLI values suggested that the one-factor model had an acceptable fit to the data in the total sample $(\mathrm{CFI}=.982, \mathrm{TLI}=.969, \mathrm{RMSEA}=.088$ [90\%CI .069-.109]), and the PPU latent factor was well-defined by strong factor loadings (Table 2$)^{2}$. Descriptive statistics for each variable are presented in Table 3. The PPCS-6-A demonstrated adequate reliability $(\alpha=.80 ; \mathrm{CR}=.90)$.

To further support the validity of the PPCS-6-A and ensure that gender-based comparisons are meaningful, we examined the invariance of the PPCS-6-A across two groups of adolescents (boys vs. girls). First, we estimated the baseline models. Then, parameters were gradually constrained, and changes in the fit indices were examined. The changes in the fit indices suggested that latent variance invariance was achieved, but latent mean invariance was not, suggesting the presence of latent mean differences between boys and girls (Table 1$)^{3}$. When we constrained boys' latent means to zero for model identification, girls' latent means were substantially lower $(-0.70 \mathrm{SD}, p<.001)$. As only three $(0.4 \%)$ adolescents reported being non-

\footnotetext{
${ }^{2}$ When inspecting the modification indices (MI), the covariance between Item 1 and Item 2 had a MI of 44.08, Item 3 and Item 6 had a MI of 21.65, and Item 2 and Item 3 had a MI of 13.95. However, we did not include any error covariances in the CFA model as previous recommendations suggest that error covariances should be included in models based on clear empirical findings and robust theory; when the same items are assessed on multiple occasions (e.g., longitudinal designs); or when strictly parallel items are used to measure different constructs (e.g., using the same items for math and reading self-concept); thus, adding post hoc correlated uniquenesses without proper justification should be avoided (Marsh, 2007; Marsh et al., 2010).

${ }^{3}$ As the sample sizes were unequal in the examined groups (i.e., the sample size in the girls group was approximately half of the boys group), we also conducted the measurement invariance test using a random sample from the boys' group that matched the sample size of the girls' group. The results did not change substantially, latent variance invariance was achieved, but latent mean invariance was not, suggesting the presence of latent mean differences between boys and girls.
} 
binary, gender fluid, or something else, and one $(0.1 \%)$ selected the "other" answer option, we could not include them in the measurement invariance testing as a separate group. The group of non-binary or gender fluid adolescents reported a mean of $6.67(S D=1.16)$, and the one adolescent who selected the "other" answer option reported a mean of 15.00 on the PPCS-6-A.

In the next step, we examined the invariance of the PPCS-6-A across two groups of adolescents (heterosexual vs. sexual minority) to ensure that sexual orientation-based comparisons are meaningful. In this case, the changes in the fit indices suggested that latent mean invariance was achieved, indicating that the PPCS-6-A appears to function the same way in heterosexual and sexual minority adolescents (Table 1$)^{4}$.

\section{Associations of the PPCS-6-A with Theoretically Relevant Correlates}

As presented in Table 3, PPU had a positive, moderate association with the frequency of pornography use $(r=.48, p<.001)$ and the frequency of masturbation $(r=.33, p<.001)$ in the past three months. PPU scores were positively and weakly related to all indicators of sexual interest and arousal, including sexual thoughts $(r=.23, p<.001)$, sexual drive $(r=.22, p<.001)$, and sexual arousal $(r=.20, p<.001)$. PPU also had a positive, small association with sexual distress $(r=.16, p=.001)$. PPU was weakly and negatively associated with age at first pornography use $(r=-.26, p<.001)$. These associations were similar in boys and girls (Table S1, online supplementary material), and in heterosexual and sexual minority adolescents (Table S2, online supplementary material).

\section{Identification of At-Risk Problematic Pornography Users}

\footnotetext{
${ }^{4}$ As the sample sizes were unequal in the examined groups (i.e., the sample size in the sexual minority adolescents group was approximately one-sixth of the heterosexual adolescents group), we also conducted the measurement invariance test using a random sample from the heterosexual adolescents group that was similar to the sample size of the sexual minority adolescents group. The results did not change substantially, latent mean invariance was achieved, suggesting the scale functions the same way in these groups.
} 
We performed latent profile analyses on the six items of the PPCS-6-A to identify potential subgroups of problematic pornography users (Table 4). The AIC, CAIC, BIC, and SSABIC values decreased continuously as more latent classes were added to the models. Regarding entropy, all solutions had high accuracy. The non-significant aLMR Test suggested that the three class-solution should be rejected, and the two-class solution should be retained. The inspection of all solutions showed that adding a second class resulted in theoretically meaningful, distinct, and interpretable classes, but adding a third (or fourth) class simply led to the arbitrary division of one class into two smaller ones with similar shapes. Thus, we retained the two-class solution in which the first class included $89.7 \%(n=714)$ of the adolescents and represented lowrisk problematic pornography users, and the second class included $10.3 \%$ of the adolescents $(n=$ 82) and represented at-risk problematic pornography users (Figure S1, online supplementary material).

\section{Comparison of the Low-Risk and At-Risk Problematic Pornography User Profiles}

To examine the differences between the previously identified two classes, we compared age at first pornography use, frequency of pornography use and masturbation, sexual interest and arousal, sexual distress, gender, and sexual orientation between the two classes (Table 5). The atrisk problematic pornography users reported significantly higher levels of sexual interest and arousal and sexual distress, higher frequency of pornography use and masturbation, and younger age at first pornography use, compared with the low-risk problematic pornography users (all $p \mathrm{~s}<$ .012). The at-risk problematic pornography users group included significantly more boys than girls $(p<.001)$, but no significant differences were observed in the ratio of heterosexual and sexual minority adolescents in the two groups $(p=.439)$. Furthermore, we examined item endorsement and frequency count for all items of the PPCS-6-A in the two groups. A total of 47.9 to $92.0 \%$ of adolescents in the low-risk problematic pornography users group selected the 
"never" answer option, whereas only 6.1 to $34.1 \%$ selected it in the at-risk problematic pornography users group (Table 6). Moreover, in the at-risk problematic pornography users group, 35 adolescents (out of 82; 42.7\%) endorsed all six items at a non-zero level (i.e., chose other than the "never" answer option for all items), whereas 11 adolescents (out of $714 ; 1.5 \%$ ) did so in the low-risk problematic pornography users group (Table 7).

\section{Discussion}

Despite the high prevalence of pornography use in adolescents (Peter \& Valkenburg, 2016) and increasing scientific interest in adolescents’ PPU (Kohut \& Štulhofer, 2018; Štulhofer et al., 2020), there was no systematically validated PPU scale in the literature in an adolescent population. The present study addressed this shortcoming by thoroughly examining the psychometric properties of the PPCS-6-A in a large, diverse sample of adolescents. The PPCS-6A can be considered a short, reliable, and valid scale to assess PPU among adolescents and may distinguish between adolescents at low-risk or at-risk of experiencing PPU.

In line with recent methodological suggestions (Kohut et al., 2019; Koletić, 2017), a thorough examination of the PPCS-6-A was conducted to assess the scale's reliability and validity in a comprehensive sample of adolescents. Our results support the unidimensionality of the PPCS in adolescents, corroborating results of prior studies with adults (Bőthe, Tóth-Király, Demetrovics, et al., 2020). Moreover, in line with adult findings (Bőthe, Lonza, et al., 2020; Bőthe, Potenza, Griffiths, et al., 2020; Bőthe, Tóth-Király, Demetrovics, et al., 2020; Chen et al., 2021; Chen \& Jiang, 2020), the PPCS-6-A demonstrated excellent reliability in terms of Cronbach's alpha and composite reliability, supporting that all items assess the same underlying construct (i.e., PPU).

In previous studies, important gender and sexual orientation-based differences were reported in adolescents' pornography use (Bőthe, Vaillancourt-Morel, et al., 2019; Böthe, 
Vaillancourt-Morel, Girouard, et al., 2020; Peter \& Valkenburg, 2016). The present results of measurement invariance testing indicated that the PPCS-6-A functions similarly in boys and girls, although boys had higher PPU scores than girls, corroborating previous findings in adults (Bőthe, Tóth-Király, Demetrovics, et al., 2020; Bőthe, Tóth-Király, et al., 2018; Grubbs, Kraus, et al., 2019; Rissel et al., 2017) and adolescents (Cho, 2016; Efrati \& Dannon, 2019; Efrati \& Gola, 2018). Concerning sexual orientation, the highest level of measurement invariance was achieved, supporting the validity of the scale for all sexual orientations and indicating that heterosexual and sexual minority adolescents reported similar levels of PPU in general, reflecting the findings of the original validation study with adults (Bőthe, Tóth-Király, Demetrovics, et al., 2020). The PPCS-6-A may be used reliably in future adolescent studies assessing PPU, and the differences in PPU scores may be attributed to actual differences between gender and sexual orientation-based groups, and not measurement biases.

Based on correlational results, higher levels of PPU were associated with more frequent pornography use and masturbation, with moderate effect sizes, in line with prior studies among adults and adolescents (Bőthe et al., 2017; Bőthe, Tóth-Király, et al., 2018; Bőthe, Tóth-Király, Demetrovics, et al., 2020; Bőthe et al., 2021; Grubbs, Perry, et al., 2019; Kohut \& Štulhofer, 2018). Moreover, higher levels of PPU were related to higher levels of sexual interest and arousal and sexual distress, with small effect sizes, corroborating prior findings among adults (Böthe et al., 2021; Leonhardt et al., 2020; Wéry \& Billieux, 2016). Higher levels of PPU were associated with younger age at first pornography use, with a small effect size, similarly to prior studies examining treatment seeking and non-treatment seeking adults (Gola et al., 2016; Lewczuk et al., 2017). Given that previous research focused mainly on heterosexual men and boys (Böthe, Vaillancourt-Morel, et al., 2019; Grubbs et al., 2020; Kowalewska et al., 2020) which may lead to inappropriate generalizations stemming from results based on heterosexual male samples 
(Klein et al., 2014; Montgomery-Graham, 2017), it was deemed necessary to report findings for each subgroup of adolescents separately as well. Correlations were similar in all examined subgroups (i.e., boys, girls, heterosexual, and sexual minority adolescents), supporting the validity of the PPCS-6-A in all groups. However, future studies are needed to examine further the scale's clinical validity, utility, and temporal stability in adolescent samples.

According to the results of the latent profile analysis, two groups of adolescents were identified based on their levels of PPU, with one group including adolescents (approximately $90 \%$ of the sample) who might be at low risk of experiencing PPU, and the other group, adolescents (approximately 10\% of the sample) who might be at risk of experiencing PPU. Adolescents in the at-risk PPU group reported similar PPU scores as treatment-seeking and treatment considering individuals in previous studies (Böthe, Lonza, Štulhofer, et al., 2020; Bőthe, Tóth-Király, Demetrovics, et al., 2020). In line with prior findings (Cho, 2016; Efrati \& Dannon, 2019; Efrati \& Gola, 2018; Vaillancourt-Morel et al., 2017), the at-risk PPU group included significantly more boys, but no sexual orientation-related differences were identified between the low-risk and at-risk PPU groups. Moreover, the at-risk PPU group started to use pornography from a younger age, had higher levels of PPU, greater sexual interest, arousal, and distress, and used pornography and masturbated more frequently than adolescents in the low-risk PPU group. These findings are in line with those of previous studies with adults comparing individuals with low-risk and high-risk of PPU (Bőthe, Tóth-Király, et al., 2018; Bőthe, TóthKirály, Demetrovics, et al., 2020; Seok \& Sohn, 2015; Voon et al., 2014).

Nevertheless, it should be noted that prior person-centered studies with adults identifying individuals with PPU (Bőthe, Tóth-Király, et al., 2018; Bőthe, Tóth-Király, Potenza, et al., 2020; Vaillancourt-Morel et al., 2017) and studies with adolescents examining compulsive sexual behaviors (Efrati \& Dannon, 2019; Efrati \& Gola, 2018) reported three potential groups of users, 
with one of them being the problematic or compulsive user group. In these studies (Böthe, TóthKirály, Demetrovics, et al., 2020; Bőthe, Tóth-Király, et al., 2018; Bőthe, Tóth-Király, Potenza, et al., 2020; Efrati \& Dannon, 2019; Efrati \& Gola, 2018; Vaillancourt-Morel et al., 2017), approximately $3 \%$ to $14 \%$ of the users belonged to the at-risk PPU group. Although only two groups of adolescents were identified in the present study based on their levels of PPU, a similar ratio, $10 \%$ of adolescents, belonged to the at-risk PPU group, as reported in prior studies. These results are also in line with the findings of a recent two-wave longitudinal study examining PPU in a sample of older adolescent boys (Štulhofer et al., 2020), reporting that $12 \%$ of boys were included in the at-risk group at each measurement point. However, only $5 \%$ of adolescent boys reported PPU consistently over a five-month period, suggesting a high "fluidity" in adolescents' perceived PPU (Štulhofer et al., 2020), warranting further examination, especially using longitudinal designs.

\section{Limitations and Future Studies}

To the best of our knowledge, this is the first study that systematically examined the psychometric properties of a scale assessing PPU in a comprehensive sample of adolescents, including all sexual orientations. However, the present study had some limitations, such as the use of cross-sectional, self-reported data on a self-selected sample that may be prone to biases (e.g., social desirability or recall bias, and under-reporting or over-reporting). Although the present sample was large and diverse in terms of gender, sexual orientation, and cultural identity, it was not representative of all adolescents in the country; thus, the findings may not be generalized to all adolescents. Moreover, the number of non-binary adolescents was low, limiting the conclusions that can be drawn from the present findings. Moral incongruence was not assessed in this study, which may also limit generalizability, as moral incongruence may be associated with self-perceived PPU in some cases (Grubbs, Perry, et al., 2019; Grubbs \& Perry, 
2019). The present study only assessed intentional pornography use; unwanted exposure to pornography was not examined. Each component of sexual interest and arousal (i.e., sexual thoughts, drive, and arousal) was assessed with one item that may bias the findings. Future studies are needed to further examine the construct and clinical validity of the PPCS-6-A, and PPU-related functional impairment in different samples of adolescents (e.g., in different cultures or treatment-seeking settings; Chen et al., 2021; Chen \& Jiang, 2020). Longitudinal studies would be necessary to examine the temporal stability of the PPCS-6-A (Fernandez \& Griffiths, 2019; Štulhofer et al., 2020) and to examine the natural course of PPU among adolescents, as previous findings suggest that adolescents' reports of PPU may significantly change over five months (Štulhofer et al., 2020).

\section{Conclusions}

The PPCS-6-A is a theory-based (Bőthe, Tóth-Király, Demetrovics, et al., 2020; Bőthe, Tóth-Király, et al., 2018; Griffiths, 2005), short, reliable, and valid measure to assess adolescents' PPU, including adolescents with all genders and sexual orientations. The PPCS-6-A may distinguish between low-risk and potentially at-risk problematic pornography user groups, as approximately $10 \%$ of adolescents were identified as potentially being at risk for using pornography in a problematic manner. These findings may also reduce public concerns about pornography use in itself being problematic for everyone (Bőthe, Tóth-Király, Potenza, et al., 2020; Nelson \& Rothman, 2020). The PPCS-6-A can be applied in future studies to gain more accurate knowledge about the prevalence of PPU and better understand risk and protective factors as well as the potential consequences of adolescents' PPU.

\section{References}

Asparouhov, T., \& Muthén, B. O. (2007). Wald test of mean equality for potential latent class predictors in mixture modeling. Technical Report. Muthén \& Muthén. 
Ballester-Arnal, R., Gil-Llario, M. D., Giménez-García, C., Castro-Calvo, J., \& Cardenas-López, G. (2017). Sexuality in the internet era: Expressions of Hispanic adolescent and young people. Sexual Addiction and Compulsivity, 24(3), 140-155.

Bauer, G. R., Braimoh, J., Scheim, A. I., \& Dharma, C. (2017). Transgender-inclusive measures of sex/gender for population surveys: Mixed methods evaluation and recommendations. PLoS ONE, 12(5), 1-28.

Billieux, J., Flayelle, M., Rumpf, H.-J., \& Stein, D. J. (2019). High involvement versus pathological involvement in video games: a crucial distinction for ensuring the validity and utility of gaming disorder. Current Addiction Reports, 6(3), 323-330.

Borgogna, N. C., Duncan, J., \& McDermott, R. C. (2018). Is scrupulosity behind the relationship between problematic pornography viewing and depression, anxiety, and stress? Sexual Addiction \& Compulsivity, 25(4), 293-318.

Borgogna, N. C., McDermott, R. C., Browning, B. R., Beach, J. D., \& Aita, S. L. (2019). How Does Traditional Masculinity Relate to Men and Women's Problematic Pornography Viewing? Sex Roles, 80(11-12), 693-706.

Bőthe, B., Tóth-Király, I., Potenza, M. N., Griffiths, M. D., Orosz, G., \& Demetrovics, Z. (2019). Revisiting the role of impulsivity and compulsivity in problematic sexual behaviors. Journal of Sex Research, 56(2), 166-179.

Bőthe, B., Bartók, R., Tóth-Király, I., Reid, R. C., Griffiths, M. D., Demetrovics, Z., \& Orosz, G. (2018). Hypersexuality, gender, and sexual orientation: A large-scale psychometric survey study. Archives of Sexual Behavior, 47(8), 2265-2276.

Bőthe, B., Koós, M., Tóth-Király, I., Orosz, G., \& Demetrovics, Z. (2019). Investigating the associations of adult ADHD symptoms, hypersexuality, and problematic pornography use among men and women on a largescale, non-clinical sample. Journal of Sexual Medicine, 16(4), 489-499.

Bőthe, B., Lonza, A., Štulhofer, A., \& Demetrovics, Z. (2020). Symptoms of problematic pornography use in a sample of treatment considering and treatment non-considering men: A network approach. Journal of Sexual Medicine, 17(10), 2016-2028. 
Bőthe, B., Potenza, M. N., Griffiths, M. D., Kraus, S. W., Klein, V., Fuss, J., \& Demetrovics, Z. (2020). The development of the Compulsive Sexual Behavior Disorder Scale (CSBD-19): An ICD-11 based screening measure across three languages. Journal of Behavioral Addictions, 9(2), 247-258.

Bőthe, B., Tóth-Király, I., Bella, N., Potenza, M. N., Demetrovics, Z., \& Orosz, G. (2020). Why do people watch pornography? The motivational basis of pornography use. Psychology of Addictive Behaviors, 1-10.

Bőthe, B., Tóth-Király, I., Demetrovics, Z., \& Orosz, G. (2017). The pervasive role of sex mindset: Beliefs about the malleability of sexual life is linked to higher levels of relationship satisfaction and sexual satisfaction and lower levels of problematic pornography use. Personality and Individual Differences, 117, 15-22.

Böthe, B., Tóth-Király, I., Demetrovics, Z., \& Orosz, G. (2020). The short version of the Problematic Pornography Consumption Scale (PPCS-6): A reliable and valid measure in general and treatment-seeking populations. Journal of Sex Research, 1-11.

Bőthe, B., Tóth-Király, I., Griffiths, M. D., Potenza, M. N., Orosz, G., \& Demetrovics, Z. (2021). Are sexual functioning problems associated with frequent pornography use and/or problematic pornography use? Results from a large community survey including males and females. Addictive Behaviors, 112, 1-9.

Bőthe, B., Tóth-Király, I., Potenza, M. N., Griffiths, M. D., Orosz, G., \& Demetrovics, Z. (2019). Revisiting the role of impulsivity and compulsivity in problematic sexual behaviors. Journal of Sex Research, 56(2), 166-179.

Bőthe, B., Tóth-Király, I., Potenza, M. N., Orosz, G., \& Demetrovics, Z. (2020). High-frequency pornography use may not always be problematic. Journal of Sexual Medicine, 17(4), 793811.

Bőthe, B., Tóth-Király, I., Zsila, Á., Griffiths, M. D., Demetrovics, Z., \& Orosz, G. (2018). The development of the Problematic Pornography Consumption Scale (PPCS). Journal of Sex Research, 55(3), 395-406.

Böthe, B., Vaillancourt-Morel, M.-P., Bergeron, S., \& Demetrovics, Z. (2019). Problematic and 
non-problematic pornography use among LGBTQ adolescents: A systematic literature review. Current Addiction Reports, 6(4), 478-494.

Bőthe, B., Vaillancourt-Morel, M.-P., Girouard, A., Štulhofer, A., Dion, J., \& Bergeron, S. (2020). A large-scale comparison of Canadian sexual/gender minority and heterosexual, cisgender adolescents' pornography use characteristics. Journal of Sexual Medicine, 17(6), $1156-1167$.

Browne, M. W., \& Cudeck, R. (1993). Alternative ways of assessing model fit. Testing Structural Equation Models, 21(2), 136-162.

Chen, F., Curran, P. J., Bollen, K. A., Kirby, J., \& Paxton, P. (2008). An empirical evaluation of the use of fixed cutoff points in RMSEA test statistic in structural equation models. Sociological Methods and Research, 36(4), 462-494.

Chen, F. F. (2007). Sensitivity of goodness of fit indexes to lack of measurement invariance. Structural Equation Modeling, 14(3), 464-504.

Chen, L., \& Jiang, X. (2020). The assessment of problematic internet pornography use: A comparison of three scales with mixed methods. International Journal of Environmental Research and Public Health, 17(2), 488.

Chen, L., Luo, X., Bőthe, B., Jiang, X., Demetrovics, Z., \& Potenza, M. N. (2021). Properties of the Problematic Pornography Consumption Scale (PPCS-18) in community and subclinical samples in China and Hungary. Addictive Behaviors, 112, 106591.

Cheung, G. W., \& Rensvold, R. B. (2002). Evaluating goodness-of-fit indexes for testing measurement invariance. Structural Equation Modeling, 9(2), 233-255.

Cho, E. (2016). Frequent internet pornography use: Korean adolescents' internet use time, mental health, sexual behavior, and delinquency. International Journal of Human Ecology, 17(1), $27-37$.

Cohen, J. (1992). A power primer. Psychological Bulletin, 112(1), 155-159.

Collins, L. M., \& Lanza, S. T. (2010). Latent class and latent transition analysis: with applications in the social, behavioral, and health sciences (pp. 1-295). Wiley.

Dawson, K., Nic Gabhainn, S., \& MacNeela, P. (2019). Toward a model of porn literacy: Core 
concepts, rationales, and approaches. Journal of Sex Research, 1-15.

Derogatis, L. R., Rosen, R., Leiblum, S., Burnett, A., \& Heiman, J. (2002). The Female Sexual Distress Scale (FSDS): Initial validation of a standardized scale for assessment of sexually related personal distress in women. Journal of Sex \& Marital Therapy, 28(4), 317-330.

Doornwaard, S. M., Van Den Eijnden, R. J. J. M., Baams, L., Vanwesenbeeck, I., \& Ter Bogt, T. F. M. (2016). Lower psychological well-being and excessive sexual interest predict symptoms of compulsive use of sexually explicit internet material among adolescent boys. Journal of Youth and Adolescence, 45, 73-84.

Efrati, Y. (2018). Adolescents with a disposition toward compulsive sexual behavior: The role of shame in willingness to seek help and treatment. Sexual Addiction and Compulsivity, 25(1), $28-45$

Efrati, Y. (2020). Problematic and non-problematic pornography use and compulsive sexual behaviors among understudied populations: Children and adolescents. Current Addiction Reports, 7(1), 68-75.

Efrati, Y., \& Dannon, P. (2019). Normative and clinical self-perceptions of sexuality and their links to psychopathology among adolescents. Psychopathology, 51(6), 380-389.

Efrati, Y., \& Gola, M. (2018). Understanding and predicting profiles of compulsive sexual behavior among adolescents. Journal of Behavioral Addictions, 7(4), 1004-1014.

Fernandez, D. P., \& Griffiths, M. D. (2019). Psychometric instruments for problematic pornography use: A systematic review. Evaluation and the Health Professions, 1-71.

Finney, S. J., \& DiStefano, C. (2013). Non-normal and categorical data in structural equation modeling. In G. R. Hancock \& R. O. Mueller (Eds.), Structural equation modeling: A second course (2nd ed., pp. 439-492). Information Age Publishing.

Gola, M., Lewczuk, K., \& Skorko, M. (2016). What matters: Quantity or quality of pornography use? Psychological and behavioral factors of seeking treatment for problematic pornography use. Journal of Sexual Medicine, 13(5), 815-824.

Griffiths, M. D. (2005). A “components" model of addiction within a biopsychosocial framework. Journal of Substance Use, 10(4), 191-197. 
Grubbs, J. B., \& Gola, M. (2019). Is pornography use related to erectile functioning? Results from cross-sectional and latent growth curve analyses. Journal of Sexual Medicine, 16(1), $111-125$.

Grubbs, J. B., Kraus, S. W., \& Perry, S. L. (2019). Self-reported addiction to pornography in a nationally representative sample: The roles of use habits, religiousness, and moral incongruence. Journal of Behavioral Addictions, 8(1), 88-93.

Grubbs, J. B., \& Perry, S. L. (2019). Moral incongruence and pornography use: A critical review and integration. Journal of Sex Research, 56(1), 29-37.

Grubbs, J. B., Perry, S. L., Wilt, J. A., \& Reid, R. C. (2019). Pornography problems due to moral incongruence: An integrative model with a systematic review and meta-analysis. Archives of Sexual Behavior, 48(2), 397-415.

Grubbs, J. B., Stauner, N., Exline, J. J., Pargament, K. I., \& Lindberg, M. J. (2015). Perceived addiction to internet pornography and psychological distress: Examining relationships concurrently and over time. Psychology of Addictive Behaviors, 29(4), 1056-1067.

Grubbs, J., Hoagland, C., Lee, B., Grant, J., Davison, P. M., Reid, R., \& Kraus, S. W. (2020). Sexual addiction 25 years on: A systematic and methodological review of empirical literature and an agenda for future research. Clinical Psychology Review, 1-15.

Haynes, S. N., Richard, D. C. S., \& Kubany, E. S. (1995). Content validity in psychological assessment: A functional approach to concepts and methods. In Psychological Assessment (Vol. 7, Issue 3, pp. 238-247).

Kafka, M. P. (2010). Hypersexual disorder: A proposed diagnosis for DSM-V. Archives of Sexual Behavior, 39(2), 377-400.

Keen, C., France, A., \& Kramer, R. (2020). Exposing children to pornography: How competing constructions of childhood shape state regulation of online pornographic material. New Media \& Society, 22(5), 1-18.

Kenny, D. A., Kaniskan, B., \& McCoach, D. B. (2015). The Performance of RMSEA in Models With Small Degrees of Freedom. Sociological Methods and Research, 44(3), 486-507. Klein, V., Rettenberger, M., \& Briken, P. (2014). Self-reported indicators of hypersexuality and 
its correlates in a female online sample. Journal of Sexual Medicine, 11(8), 1974-1981.

Kohut, T., Balzarini, R. N., Fisher, W. A., \& Campbell, L. (2018). Pornography's associations with open sexual communication and relationship closeness vary as a function of dyadic patterns of pornography use within heterosexual relationships. Journal of Social and Personal Relationships, 35(4), 655-676.

Kohut, T., Balzarini, R. N., Fisher, W. A., Grubbs, J. B., Campbell, L., \& Prause, N. (2019). Surveying pornography use: A shaky science resting on poor measurement foundations. Journal of Sex Research, 1-21.

Kohut, T., \& Štulhofer, A. (2018). The role of religiosity in adolescents' compulsive pornography use: A longitudinal assessment. Journal of Sex and Marital Therapy, 44(8), 759-775.

Koletić, G. (2017). Longitudinal associations between the use of sexually explicit material and adolescents' attitudes and behaviors: A narrative review of studies. Journal of Adolescence, $57,119-133$.

Kor, A., Fogel, Y. A., Reid, R. C., \& Potenza, M. N. (2013). Should Hypersexual Disorder be Classified as an Addiction? Sexual Addiction and Compulsivity, 20(1-2), 27-47.

Kor, A., Zilcha-Mano, S., Fogel, Y. A., Mikulincer, M., Reid, R. C., \& Potenza, M. N. (2014). Psychometric development of the Problematic Pornography Use Scale. Addictive Behaviors, 39(5), 861-868.

Kowalewska, E., Gola, M., Kraus, S. W., \& Lew-starowicz, M. (2020). Spotlight on Compulsive Sexual Behavior Disorder : A Systematic Review of Research on Women. Neuropsychiatric Disease and Treatment, 16, 2025-2043.

Kraus, S. W., Gola, M., Grubbs, J. B., Kowalewska, E., Hoff, R. A., Lew-Starowicz, M., Martino, S., Shirk, S. D., \& Potenza, M. N. (2020). Validation of a brief pornography screen across multiple samples. Journal of Behavioral Addictions, 9(2), 259-271.

Kraus, S. W., Krueger, R. B., Briken, P., First, M. B., Stein, D. J., Kaplan, M. S., Voon, V., Abdo, C. H. N. N., Grant, J. E., Atalla, E., \& Reed, G. M. (2018). Compulsive sexual behaviour disorder in the ICD-11. World Psychiatry, 17(1), 109-110.

Kraus, S. W., Voon, V., \& Potenza, M. N. (2016). Additional challenges and issuesin classifying 
compulsive sexual behavior as an addiction. Journal of Sex Research, 111(9), 181-198.

Leonhardt, N. D., Busby, D. M., \& Willoughby, B. J. (2020). Do you feel in control? Sexual desire, sexual passion expression, and associations with perceived compulsivity to pornography and pornography use frequency. Sexuality Research and Social Policy, 1-13.

Lewczuk, K., Szmyd, J., Skorko, M., \& Gola, M. (2017). Treatment seeking for problematic pornography use among women. Journal of Behavioral Addictions, 6(4), 445-456. https://doi.org/10.1556/2006.6.2017.063

Lewczuk, K., Wojcik, A., \& Gola, M. (2019). Increase in the prevalence of online pornography use - objective data analysis from the period between 2004 and 2016 in Poland. 1-45.

Lobe, B., Livingstone, S., Ólafsson, K., \& Vodeb, H. (2011). Cross-national comparison of risks and safety on the internet: Initial analysis from the EU Kids Online survey of European children.

Lubke, G., \& Muthén, B. O. (2007). Performance of factor mixture models as a function of model size, covariate effects, and class-specific parameters. Structural Equation Modeling: A Multidisciplinary Journal, 14(1), 26-47.

Marsh, H. W., Ellis, L. A., Parada, R. H., Richards, G., \& Heubeck, B. G. (2005). A Short Version of the Self Description Questionnaire II : Operationalizing Criteria for Short-Form Evaluation With New Applications of Confirmatory Factor Analyses. Psychological Assessment, 17(1), 81-102.

Marsh, H. W. (2007). Application of Confirmatory Factor Analysis and Structural Equation Modeling in Sport and Exercise Psychology. In Handbook of Sport Psychology: Third Edition (pp. 774-798)

Marsh, H. W., Hau, K.-T., \& Grayson, D. (2005). Goodness of fit evaluation in structural equation modeling.

Marsh, H. W., Lüdtke, O., Muthén, B., Asparouhov, T., Morin, A. J. S., Trautwein, U., \& Nagengast, B. (2010). A new look at the Big Five factor structure through exploratory structural equation modeling. Psychological Assessment, 22(3), 471-491.

Marsh, H. W., Lüdtke, O., Trautwein, U., \& Morin, A. J. S. (2009). Classical latent profile 
analysis of academic self-concept dimensions: Synergy of person- and variable-centered approaches to theoretical models of self-concept. Structural Equation Modeling, 16(2), 191225.

Marsh, H. W., Vallerand, R. J., Lafreniére, M. A. K., Parker, P., Morin, A. J. S., Carbonneau, N., Jowett, S., Bureau, J. S., Fernet, C., Guay, F., Abduljabbar, A. S., \& Paquet, Y. (2013). Passion: Does one scale fit all? Construct validity of two-factor passion scale and psychometric invariance over different activities and languages. Psychological Assessment, 25(3), 796-809.

McGahuey, C. A., Gelenberg, A. J., Laukes, C. A., Moreno, F. A., Delgado, P. L., McKnight, K. M., \& Manber, R. (2000). The arizona sexual experience scale (Asex): Reliability and validity. Journal of Sex and Marital Therapy, 26(1), 25-38.

Meredith, W. (1993). Measurement invariance, factor analysis and factorial invariance. Psychometrika, 58(4), 525-543.

Milfont, T. L., \& Fischer, R. (2010). Testing measurement invariance across groups: Applications in cross- cultural research. Probando la invariancia de mediciones entre varios grupos: aplicaciones en la investigación transcultural. International Journal of Psychological Research, 3(31), 2011-2079.

Millsap, P. (2011). Statistical approaches to measurement invariance. Taylor \& Francis.

Montgomery-Graham, S. (2017). Conceptualization and assessment of hypersexual disorder: a systematic review of the literature. Sexual Medicine Reviews, 5(2), 146-162.

Morelli, M., Bianchi, D., Baiocco, R., Pezzuti, L., \& Chirumbolo, A. (2017). Sexting behaviors and cyber pornography addiction among adolescents: the moderating role of alcohol consumption. Sexuality Research and Social Policy, 14(2), 113-121.

Nelson, K. M., \& Rothman, E. F. (2020). Should public health professionals consider pornography a public health crisis? American Journal of Public Health, 110(2), 151-153.

Nunnally, J. C. (1978). Psychometric theory. McGraw-Hill series in psychology. (3rd ed.). McGraw-Hill.

Orosz, G., Tóth-Király, I., \& Bőthe, B. (2016). Four facets of Facebook intensity — The 
development of the Multidimensional Facebook Intensity Scale. Personality and Individual Differences, 100, 95-104.

Orosz, G., Tóth-Király, I., Büki, N., Ivaskevics, K., Bothe, B., Fülöp, M., Bőthe, B., \& Fülöp, M. (2018). The four faces of competition: The development of the Multidimensional Competitive Orientation Inventory. Frontiers in Psychology, 9, 1-16.

Pâquet, M., Rosen, N. O., Steben, M., Mayrand, M. H., Santerre-Baillargeon, M., \& Bergeron, S. (2018). Daily Anxiety and Depressive Symptoms in Couples Coping With Vulvodynia: Associations With Women's Pain, Women's Sexual Function, and Both Partners' Sexual Distress. Journal of Pain, 19(5), 552-561.

Perreira, T. A., Morin, A. J. S., Hebert, M., Gillet, N., Houle, S. A., \& Berta, W. (2018). The short form of the Workplace Affective Commitment Multidimensional Questionnaire (WACMQ-S): A bifactor-ESEM approach among healthcare professionals. Journal of Vocational Behavior, 106, 62-83.

Peter, J., \& Valkenburg, P. M. (2016). Adolescents and pornography: A review of 20 years of research. Journal of Sex Research, 53(4-5), 509-531.

Pizzol, D., Bertoldo, A., \& Foresta, C. (2016). Adolescents and web porn: A new era of sexuality. International Journal of Adolescent Medicine and Health, 28(2), 169-173.

Potenza, M. N., Gola, M., Voon, V., Kor, A., \& Kraus, S. W. (2017). Is excessive sexual behaviour an addictive disorder? Lancet Psychiatry, 4(9), 663-664.

Prause, N., Janssen, E., Georgiadis, J., Finn, P., \& Pfaus, J. (2017). Data do not support sex as addictive. The Lancet Psychiatry, 4(12), 899.

Raykov, T. (1997). Estimation of composite reliability for congeneric measures. Applied Psychological Measurement, 21(2), 173-184.

Rissel, C., Richters, J., de Visser, R. O., McKee, A., Yeung, A., \& Caruana, T. (2017). A profile of pornography users in Australia: Findings from the second Australian study of health and relationships. Journal of Sex Research, 54(2), 227-240.

Rousseau, A., Bőthe, B., \& Štulhofer, A. (2020). Theoretical antecedents of male adolescents' problematic pornography use: a longitudinal assessment. Journal of Sex Research, 1-38. 
Sassover, E., \& Weinstein, A. (2020). Should compulsive sexual behavior (CSB) be considered as a behavioral addiction? A debate paper presenting the opposing view. Journal of Behavioral Addictions, 1-14.

Schermelleh-Engel, K., Moosbrugger, H., \& Müller, H. (2003). Evaluating the fit of structural equation models: Tests of significance and descriptive goodness-of-fit measures. MPROnline, 8(2), 23-74.

Seok, J.-W., \& Sohn, J.-H. (2015). Neural substrates of sexual desire in individuals with problematic hypersexual behavior. Frontiers in Behavioral Neuroscience, 9, 321.

Sinković, M., Štulhofer, A., \& Božić, J. (2013). Revisiting the association between pornography use and risky sexual behaviors: The role of early exposure to pornography and sexual sensation seeking. Journal of Sex Research, 50(7), 633-641.

Spector, I. P., Carey, M. P., \& Steinberg, L. (1996). The sexual desire inventory: Development, factor structure, and evidence of reliability. Journal of Sex and Marital Therapy, 22(3), 175190.

Štulhofer, A., Rousseau, A., \& Shekarchi, R. (2020). A two-wave assessment of the structure and stability of self-reported problematic pornography use among male Croatian adolescents. International Journal of Sexual Health, 32(2), 151-164.

Svedin, C. G., Åkerman, I., \& Priebe, G. (2011). Frequent users of pornography. A population based epidemiological study of Swedish male adolescents. Journal of Adolescence, 34(4), $779-788$.

Thomas, K. A., \& Clifford, S. (2017). Validity and Mechanical Turk: An assessment of exclusion methods and interactive experiments. Computers in Human Behavior, 77, 184-197.

Tóth-Király, I., Bőthe, B., \& Orosz, G. (2018). Seeing the forest through different trees: A social psychological perspective of work addiction. Journal of Behavioral Addictions, 7(4), 875879.

Tóth-Király, I., Vallerand, R. J., Bőthe, B., Rigó, A., \& Orosz, G. (2019). Examining sexual motivation profiles and their correlates using latent profile analysis. Personality and Individual Differences, 146, 76-86. 
Vaillancourt-Morel, M.-P., Blais-Lecours, S., Labadie, C., Bergeron, S., Sabourin, S., \& Godbout, N. (2017). Profiles of cyberpornography use and sexual well-being in adults. Journal of Sexual Medicine, 14(1), 78-85.

Vandenberg, R. J., \& Lance, C. E. (2000). A review and synthesis of the measurement invariance literature: Suggestions, practices, and recommendations for organizational research. Organizational Research Methods, 3(1), 4-70.

Voon, V., Mole, T. B., Banca, P., Porter, L., Morris, L., Mitchell, S., Lapa, T. R., Karr, J., Harrison, N. A., Potenza, M. N., \& Irvine, M. (2014). Neural correlates of sexual cue reactivity in individuals with and without compulsive sexual behaviours. PLoS ONE, 9(7).

Weinrich, J. D. (2014). On the Design, Development, and Testing of Sexual Identity Questions: A Discussion and Analysis of Kristen Miller and J. Michael Ryan's Work for the National Health Interview Survey. Journal of Bisexuality, 14, 502-523.

Wéry, A., \& Billieux, J. (2016). Online sexual activities: An exploratory study of problematic and non-problematic usage patterns in a sample of men. Computers in Human Behavior, 56, $257-266$.

Wolak, J., Mitchell, K., \& Finkelhor, D. (2007). Unwanted and wanted exposure to online pornography in a national sample of youth Internet users. Pediatrics, 119(2), 247-257.

World Health Organization. (2019). International statistical classification of diseases and related health problems (11th ed.). 
Table 1

Confirmatory Factor Analyses (CFA) and Tests of Measurement Invariance on the Short Version of the Problematic Pornography Consumption Scale in Adolescents (PPCS-6-A)

\begin{tabular}{|c|c|c|c|c|c|c|c|c|c|c|}
\hline Model & WLSMV $\chi^{2}(\mathrm{df})$ & CFI & TLI & RMSEA & $90 \% \mathrm{CI}$ & Comparison & $\Delta \chi^{2}(\mathrm{df})$ & $\Delta \mathrm{CFI}$ & $\Delta \mathrm{TLI}$ & $\triangle \mathrm{RMSEA}$ \\
\hline One-factor CFA & $65.002 *(9)$ & .982 & .969 & .088 & $.069-.109$ & - & - & - & - & - \\
\hline \multicolumn{11}{|c|}{ Gender-based Invariance $\left(n_{\text {boys }}=513 ; n_{\text {girls }}=279\right)$} \\
\hline M1G. Configural & $71.738 *(18)$ & .984 & .974 & .087 & $.066-.108$ & - & - & - & - & - \\
\hline M2G. Metric & $78.511 *(23)$ & .984 & .979 & .078 & $.060-.097$ & M2-M1 & $10.636(5)$ & .000 & +.005 & -.009 \\
\hline M3G. Scalar & $103.859 *(50)$ & .984 & .990 & .052 & $.038-.066$ & M3-M2 & $39.687(27)$ & .000 & +.011 & -.026 \\
\hline M4G. Residual & $114.141 *(56)$ & .983 & .991 & .051 & $.038-.065$ & M4-M3 & $14.347 *(6)$ & -.001 & +.001 & -.001 \\
\hline M5G. Latent variance & $134.897 *(57)$ & .977 & .988 & .059 & $.046-.072$ & M5-M4 & $9.251 *(1)$ & -.006 & -.003 & +.008 \\
\hline M6G. Latent means & $301.337 *(58)$ & .928 & .963 & .103 & $.092-.115$ & M6-M5 & $42.478 *(1)$ & -.049 & -.025 & +.044 \\
\hline \multicolumn{11}{|c|}{ Sexual Orientation-based Invariance $\left(n_{\text {heterosexual }}=683 ; n_{\text {sexual minority }}=109\right)$} \\
\hline M1S. Configural & $57.361 *(18)$ & .989 & .982 & .074 & $.053-.096$ & & & & & \\
\hline M2S. Metric & $59.514 *(23)$ & .990 & .987 & .063 & $.044-.083$ & M2-M1 & $2.901(5)$ & +.001 & +.005 & -.011 \\
\hline M3S. Scalar & $61.662 *(47)$ & .996 & .997 & .028 & $.000-.046$ & M3-M2 & $16.418(24)$ & +.006 & +.010 & -.035 \\
\hline M4S. Residual & $65.432 *(53)$ & .997 & .998 & .024 & $.000-.042$ & M4-M3 & $5.063(6)$ & +.001 & +.001 & -.004 \\
\hline M5S. Latent variance & $71.113 *(54)$ & .995 & .997 & .028 & $.000-.045$ & M5-M4 & $2.904(1)$ & -.002 & -.001 & +.004 \\
\hline M6S. Latent means & $69.167 *(55)$ & .996 & .998 & .026 & $.000-.043$ & M6-M5 & $1.450(1)$ & +.001 & +.001 & -.002 \\
\hline
\end{tabular}

Note. WLSMV = weighted least squares mean- and variance-adjusted estimator; $\chi^{2}=$ Chi-square; $\mathrm{df}=\mathrm{degrees}$ of freedom; $\mathrm{CFI}=$ comparative fit index; TLI = Tucker-Lewis Index; RMSEA = root-mean-square error of approximation; $90 \% \mathrm{CI}=90 \%$ confidence interval of the RMSEA; $\triangle \mathrm{CFI}=$ change in CFI value compared to the preceding model; $\triangle \mathrm{TLI}=$ change in the TLI value compared to the preceding model; $\triangle \mathrm{RMSEA}=$ change in the RMSEA value compared to the preceding model. Bold letters indicate the final levels of invariance that were achieved.

$* p<.05$. 
Table 2

Standardized Factor Loadings and Descriptive Statistics of the Short Version of the Problematic Pornography Consumption Scale in Adolescents (PPCS-6-A)

\begin{tabular}{|c|c|c|c|c|c|}
\hline Items & $\begin{array}{l}\text { Factor } \\
\text { Loadings }\end{array}$ & Range & $\begin{array}{c}\text { Mean } \\
(S D)\end{array}$ & $\begin{array}{l}\text { Skewness } \\
\quad(S E)\end{array}$ & $\begin{array}{l}\text { Kurtosis } \\
\quad(S E)\end{array}$ \\
\hline 1. I feel that porn is a big part of my life. (Salience) & .75 & $1-7$ & $\begin{array}{c}1.99 \\
(1.32)\end{array}$ & $\begin{array}{c}1.56 \\
(0.09)\end{array}$ & $\begin{array}{c}2.30 \\
(0.17)\end{array}$ \\
\hline 2. I relax by watching porn. (Mood Modification) & .66 & $1-7$ & $\begin{array}{c}2.41 \\
(1.67)\end{array}$ & $\begin{array}{c}1.11 \\
(0.09)\end{array}$ & $\begin{array}{c}0.36 \\
(0.17)\end{array}$ \\
\hline $\begin{array}{l}\text { 3. I participate less than I used to in other fun activities because of the time I } \\
\text { spend watching porn. (Conflict) }\end{array}$ & .83 & $1-7$ & $\begin{array}{c}1.26 \\
(0.83)\end{array}$ & $\begin{array}{c}4.35 \\
(0.09)\end{array}$ & $\begin{array}{l}21.90 \\
(0.17)\end{array}$ \\
\hline 4. I feel that I had to watch more and more porn for satisfaction. (Tolerance) & .83 & $1-7$ & $\begin{array}{c}1.45 \\
(1.05)\end{array}$ & $\begin{array}{c}3.08 \\
(0.09)\end{array}$ & $\begin{array}{l}10.51 \\
(0.17)\end{array}$ \\
\hline $\begin{array}{l}\text { 5. When I promise myself not to watch porn anymore, I can only stop for a short } \\
\text { time. (Relapse) }\end{array}$ & .77 & $1-7$ & $\begin{array}{c}2.00 \\
(1.61)\end{array}$ & $\begin{array}{l}1.57 \\
(0.09)\end{array}$ & $\begin{array}{l}1.38 \\
(0.17)\end{array}$ \\
\hline $\begin{array}{l}\text { 6. I become stressed when something prevents me from watching porn. } \\
\text { (Withdrawal) }\end{array}$ & .82 & $1-7$ & $\begin{array}{c}1.27 \\
(0.83)\end{array}$ & $\begin{array}{c}4.09 \\
(0.09)\end{array}$ & $\begin{array}{l}19.45 \\
(0.17)\end{array}$ \\
\hline PPCS-6-A Total score & - & $6-42$ & $\begin{array}{l}10.38 \\
(5.37)\end{array}$ & $\begin{array}{c}1.97 \\
(0.09)\end{array}$ & $\begin{array}{c}5.56 \\
(0.17)\end{array}$ \\
\hline
\end{tabular}

Note. All factor loadings are standardized. Loadings are statistically significant at $p<.001 . S D=$ standard deviation; $S E=$ standard error. 
Table 3

Associations between the Short Version of the Problematic Pornography Consumption Scale (PPCS-6-A) with Pornography Use and Sexuality-Related Variables

\begin{tabular}{|c|c|c|c|c|c|c|c|c|c|c|}
\hline & Range & Mean $(S D)$ & 1. & 2. & 3. & 4. & 5. & 6. & 7. & 8. \\
\hline 1. Problematic pornography use & $6-42$ & $\begin{array}{l}10.38 \\
(5.37)\end{array}$ & - & & & & & & & \\
\hline $\begin{array}{l}\text { 2. Age at first pornography use } \\
\text { (in years) }\end{array}$ & $6-18$ & $\begin{array}{l}12.33 \\
(1.81)\end{array}$ & $-.26^{* *}$ & - & & & & & & \\
\hline $\begin{array}{l}\text { 3. Frequency of pornography } \\
\text { use in the past three months a }\end{array}$ & $0-7$ & $\begin{array}{c}3.54 \\
(1.96)\end{array}$ & $.48 * *$ & $-.38 * *$ & - & & & & & \\
\hline $\begin{array}{l}\text { 4. Frequency of masturbation in } \\
\text { the past three months }{ }^{b}\end{array}$ & $1-8$ & $\begin{array}{l}5.15 \\
(1.97)\end{array}$ & $.33 * *$ & $-.30 * *$ & $.72 * *$ & - & & & & \\
\hline 5. Sexual thoughts & $1-7$ & $\begin{array}{c}4.91 \\
(1.70)\end{array}$ & $.23 * *$ & $-.21 * *$ & $.23 * *$ & $.25^{* *}$ & - & & & \\
\hline 6. Sexual drive & $1-6$ & $\begin{array}{l}4.20 \\
(0.86)\end{array}$ & $.22 * *$ & $-.20 * *$ & $.26 * *$ & $.31 * *$ & $.56 * *$ & - & & \\
\hline 7. Sexual arousal & $1-6$ & $\begin{array}{l}4.14 \\
(0.82)\end{array}$ & $.20 * *$ & $-.18 * *$ & $.24 * *$ & $.25^{* *}$ & $.40 * *$ & $.46^{* *}$ & - & \\
\hline 8. Sexual distress ${ }^{c}$ & $0-4$ & $\begin{array}{c}0.71 \\
(0.73)\end{array}$ & $.16^{* *}$ & -.06 & .12 & .03 & .09 & .04 & -.02 & - \\
\hline
\end{tabular}

Note. $S D=$ standard deviation.

${ }^{\mathrm{a}} 0=$ never, $1=$ less than 1 time per month, $2=1$ time per month, $3=2-3$ times per month, $4=1$ time per month, $5=$ many times per week, $6=1$ time per day, and $7=$ many times per day; ${ }^{b} 1=$ not once in the past three months; $2=$ less than once a month; $3=$ once a month; $4=$ two to three times a month; $5=$ once a week; $6=$ several times a week; $7=$ once a day; $8=$ more than once a day; ${ }^{\mathrm{c}}$ Only sexually active adolescents completed the Sexual Distress Scale $(n=434)$.

$* p<.05 ; * * p<.01$. 
Table 4

Fit Indices for the Latent Profile Analyses

\begin{tabular}{cccccccc}
\hline Classes & AIC & CAIC & BIC & SSABIC & Entropy & L-M-R Test & $p$ \\
\hline 1 & 15076.14 & 15144.29 & 15132.29 & 15094.19 & - & - & - \\
$\mathbf{2}$ & $\mathbf{1 3 6 3 6 . 6 2}$ & $\mathbf{1 3 7 4 4 . 5 3}$ & $\mathbf{1 3 7 2 5 . 5 3}$ & $\mathbf{1 3 6 6 5 . 2 0}$ & $\mathbf{0 . 9 7}$ & $\mathbf{1 4 2 3 . 0 8}$ & $\mathbf{0 . 0 1 6}$ \\
3 & 12924.92 & 13072.59 & 13046.59 & 12964.02 & 0.94 & 710.51 & 0.380 \\
4 & 12396.88 & 12584.31 & 12551.31 & 12446.51 & 0.96 & 530.69 & 0.168 \\
\hline
\end{tabular}

Note. Classes = number of latent classes; AIC = Akaike Information Criterion; CAIC = biascorrected Akaike Information Criterion; BIC = Bayesian Information Criterion; SSABIC = Sample-Size Adjusted Bayesian Information Criterion; L-M-R test = Lo-Mendell-Rubin Adjusted Likelihood Ratio Test; $p=p$ value associated with the L-M-R Test. Bold letters indicate that the two-class solution was selected as the final model.

\section{Table 5}

Comparison of Low-Risk and At-Risk Problematic Pornography Use Profiles in Relation to Gender, Sexual Orientation, Pornography Use, and Sexuality-Related Variables

\begin{tabular}{|c|c|c|c|c|}
\hline Variable & $\begin{array}{c}(1) \\
\text { Low-risk problematic } \\
\text { pornography users } \\
(n=714 ; 89.7 \%) \\
M(95 \% \mathrm{CI})\end{array}$ & $\begin{array}{c}(2) \\
\text { At-risk problematic } \\
\text { pornography users } \\
(n=82 ; 10.3 \%) \\
M(95 \% \mathrm{CI})\end{array}$ & $\begin{array}{c}\text { Wald } \\
\chi^{2} \text { tests }\end{array}$ & $p$ \\
\hline 1. Problematic pornography use & $9.02(8.77-9.28)$ & $22.10(20.87-23.34)$ & 416.39 & $<.001$ \\
\hline 2. Age at first pornography use (in years) & $12.42(12.28-12.56)$ & $11.51(11.08-11.94)$ & 16.04 & $<.001$ \\
\hline $\begin{array}{l}\text { 3. Frequency of pornography use in the } \\
\text { past three months a }\end{array}$ & $3.34(3.20-3.48)$ & $5.36(5.07-5.65)$ & 148.38 & $<.001$ \\
\hline $\begin{array}{l}\text { 4. Frequency of masturbation in the past } \\
\text { three months b }\end{array}$ & $5.01(4.87-5.16)$ & $6.44(6.14-6.74)$ & 70.19 & $<.001$ \\
\hline 5. Sexual thoughts & $4.81(4.67-4.95)$ & $5.86(5.57-6.15)$ & 40.06 & $<.001$ \\
\hline 6. Sexual drive & $4.14(4.08-4.21)$ & $4.68(4.49-4.87)$ & 28.11 & $<.001$ \\
\hline 7. Sexual arousal & $4.11(4.05-4.17)$ & $4.46(4.28-4.64)$ & 12.65 & $<.001$ \\
\hline 8. Sexual distress ${ }^{c}$ & $0.67(0.60-0.74)$ & $0.99(0.76-1.23)$ & 6.40 & .011 \\
\hline Variable & $\begin{array}{c}\text { (1) } \\
\text { Low-risk problematic } \\
\text { pornography users } \\
(n=714 ; 89.7 \%) \\
n(\%)\end{array}$ & $\begin{array}{c}(2) \\
\text { At-risk problematic } \\
\text { pornography users } \\
(n=82 ; 10.3 \% \%) \\
n(\%)\end{array}$ & $\chi_{\mathrm{d}}^{2}$ tests & $p$ \\
\hline 9. Gender & & & \multirow{5}{*}{21.82} & \multirow{5}{*}{$<.001$} \\
\hline Masculine/boy & $441(61.8 \%)^{2}$ & $72(87.8 \%)^{1}$ & & \\
\hline Feminine/girl & $269(37.7 \%)^{2}$ & $10(12.2 \%)^{1}$ & & \\
\hline Non-binary, gender fluid or & $3(0.4 \%)$ & $0(0.0 \%)$ & & \\
\hline Other & $1(0.1 \%)$ & $0(0.0 \%)$ & & \\
\hline 10. Sexual orientation & & & \multirow{3}{*}{0.60} & \multirow{3}{*}{.439} \\
\hline Heterosexual & $610(85.9 \%)$ & $73(89.0 \%)$ & & \\
\hline Sexual minority & $100(14.1 \%)$ & $9(11.0 \%)$ & & \\
\hline
\end{tabular}

Note. PPCS-6-A = Short Version of the Problematic Pornography Consumption Scale in Adolescents; $M=$ Mean; 95\% CI = 95\% Confidence Interval. In the case of the $\chi^{2}$ tests, superscript numbers $(1,2)$ indicate significant $(p<.05)$ difference between the given class and the indexed group within the same variable.

${ }^{a} 0=$ never, $1=$ less than 1 time per month, $2=1$ time per month, $3=2-3$ times per month, $4=1$ time per month, $5=$ many times per week, $6=1$ time per day, and $7=$ many times per day; ${ }^{\mathrm{b}} 1=$ not once in the past three months; $2=$ less than once a month; $3=$ once a month; $4=$ two to three times a month; $5=$ once a week; $6=$ several times a week; $7=$ once a day; $8=$ more than once a day; ${ }^{\mathrm{c}}$ Only sexually active adolescents completed the Sexual Distress Scale $(n=432) .{ }^{\mathrm{d}}=$ Superscript numbers indicate that groups differed significantly based on the post-hoc z-tests. 


\section{Table 6}

Endorsement and Frequency Count for the Six Items of the Short Version of the Problematic Pornography Consumption Scale (PPCS6-A) among Low-Risk Problematic Pornography Users and At-Risk Problematic Pornography Users

\section{Low-risk problematic pornography users $(n=714 ; 89.7 \%)$}

\begin{tabular}{|c|c|c|c|c|c|c|c|c|}
\hline Items & $\begin{array}{c}M \\
(S D)\end{array}$ & $\begin{array}{l}\text { Never } \\
n(\%)\end{array}$ & $\begin{array}{c}\text { Rarely } \\
n(\%)\end{array}$ & $\begin{array}{l}\text { Occasionally } \\
n(\%)\end{array}$ & $\begin{array}{l}\text { Sometimes } \\
n(\%)\end{array}$ & $\begin{array}{l}\text { Often } \\
n(\%)\end{array}$ & $\begin{array}{l}\text { Very often } \\
n(\%)\end{array}$ & $\begin{array}{l}\text { All the time } \\
n(\%)\end{array}$ \\
\hline 1. I feel that porn is a big part of my life. & $\begin{array}{c}1.75 \\
(1.05)\end{array}$ & $\begin{array}{c}398 \\
(55.7 \%)\end{array}$ & $\begin{array}{c}170 \\
(23.8 \%)\end{array}$ & $\begin{array}{c}97 \\
(13.6 \%)\end{array}$ & $\begin{array}{c}30 \\
(4.2 \%)\end{array}$ & $\begin{array}{c}16 \\
(2.2 \%)\end{array}$ & $\begin{array}{c}1 \\
(0.1 \%)\end{array}$ & $\begin{array}{c}2 \\
(0.3 \%)\end{array}$ \\
\hline 2. I relax by watching porn. & $\begin{array}{c}2.17 \\
(1.48)\end{array}$ & $\begin{array}{c}342 \\
(47.9 \%)\end{array}$ & $\begin{array}{c}139 \\
(19.5 \%)\end{array}$ & $\begin{array}{c}101 \\
(14.1 \%)\end{array}$ & $\begin{array}{c}69 \\
(9.7 \%)\end{array}$ & $\begin{array}{c}38 \\
(5.3 \%)\end{array}$ & $\begin{array}{c}10 \\
(1.4 \%)\end{array}$ & $\begin{array}{c}14 \\
(2.0 \%)\end{array}$ \\
\hline $\begin{array}{l}\text { 3. I participate less than I used to in other fun activities } \\
\text { because of the time I spend watching porn. }\end{array}$ & $\begin{array}{l}1.10 \\
(0.41)\end{array}$ & $\begin{array}{c}657 \\
(92.0 \%)\end{array}$ & $\begin{array}{c}47 \\
(6.6 \%)\end{array}$ & $\begin{array}{c}7 \\
(1.0 \%)\end{array}$ & $(0.3 \%)$ & $\begin{array}{c}0 \\
(0.0 \%)\end{array}$ & $\begin{array}{c}0 \\
(0.0 \%)\end{array}$ & $(0.1 \%)$ \\
\hline $\begin{array}{l}\text { 4. I feel that I had to watch more and more porn for } \\
\text { satisfaction. }\end{array}$ & $\begin{array}{l}1.18 \\
(0.48)\end{array}$ & $\begin{array}{c}608 \\
(85.2 \%)\end{array}$ & $\begin{array}{c}88 \\
(12.3 \%)\end{array}$ & $\begin{array}{c}14 \\
(2.0 \%)\end{array}$ & $\begin{array}{c}3 \\
(0.4 \%)\end{array}$ & $\begin{array}{c}1 \\
(0.1 \%)\end{array}$ & $\begin{array}{c}0 \\
(0.0 \%)\end{array}$ & $\begin{array}{c}0 \\
(0.0 \%)\end{array}$ \\
\hline $\begin{array}{l}\text { 5. When I promise myself not to watch porn anymore, I } \\
\text { can only stop for a short time. }\end{array}$ & $\begin{array}{c}1.72 \\
(1.32)\end{array}$ & $\begin{array}{c}486 \\
(68.1 \%)\end{array}$ & $\begin{array}{c}100 \\
(14.0 \%)\end{array}$ & $\begin{array}{c}38 \\
(5.3 \%)\end{array}$ & $\begin{array}{c}39 \\
(5.5 \%)\end{array}$ & $\begin{array}{c}35 \\
(4.9 \%)\end{array}$ & $\begin{array}{c}12 \\
(1.7 \%)\end{array}$ & $\begin{array}{c}4 \\
(0.6 \%)\end{array}$ \\
\hline $\begin{array}{l}\text { 6. I become stressed when something prevents me from } \\
\text { watching porn. }\end{array}$ & $\begin{array}{l}1.11 \\
(0.40) \\
\end{array}$ & $\begin{array}{c}656 \\
(91.9 \%) \\
\end{array}$ & $\begin{array}{c}45 \\
(6.3 \%) \\
\end{array}$ & $\begin{array}{c}10 \\
(1.4 \%) \\
\end{array}$ & $\begin{array}{c}2 \\
(0.3 \%) \\
\end{array}$ & $(0.1 \%)$ & $\begin{array}{c}0 \\
(0.0 \%) \\
\end{array}$ & $\begin{array}{c}0 \\
(0.0 \%) \\
\end{array}$ \\
\hline \multicolumn{9}{|l|}{ At-risk problematic pornography users $(n=82 ; 10.3 \%)$} \\
\hline Items & $\begin{array}{c}M \\
(S D) \\
\end{array}$ & $\begin{array}{l}\text { Never } \\
n(\%) \\
\end{array}$ & $\begin{array}{c}\text { Rarely } \\
n(\%)\end{array}$ & $\begin{array}{c}\text { Occasionally } \\
n(\%)\end{array}$ & $\begin{array}{c}\text { Sometimes } \\
n(\%)\end{array}$ & $\begin{array}{l}\text { Often } \\
n(\%) \\
\end{array}$ & $\begin{array}{c}\text { Very often } \\
n(\%)\end{array}$ & $\begin{array}{c}\text { All the time } \\
n(\%)\end{array}$ \\
\hline 1. I feel that porn is a big part of my life. & $\begin{array}{c}4.07 \\
(1.64)\end{array}$ & $\begin{array}{c}5 \\
(6.1 \%)\end{array}$ & $\begin{array}{c}8 \\
(9.8 \%)\end{array}$ & $\begin{array}{c}18 \\
(22.0 \%)\end{array}$ & $\begin{array}{c}20 \\
(24.4 \%)\end{array}$ & $\begin{array}{c}17 \\
(20.7 \%)\end{array}$ & $\begin{array}{c}4 \\
(4.9 \%)\end{array}$ & $\begin{array}{c}10 \\
(12.2 \%)\end{array}$ \\
\hline 2. I relax by watching porn. & $\begin{array}{c}4.52 \\
(1.81)\end{array}$ & $\begin{array}{c}6 \\
(7.3 \%)\end{array}$ & $\begin{array}{c}5 \\
(6.1 \%)\end{array}$ & $\begin{array}{c}14 \\
(17.1 \%)\end{array}$ & $\begin{array}{c}14 \\
(17.1 \%)\end{array}$ & $\begin{array}{c}16 \\
(19.5 \%)\end{array}$ & $\begin{array}{c}12 \\
(14.6 \%)\end{array}$ & $\begin{array}{c}15 \\
(18.3 \%)\end{array}$ \\
\hline $\begin{array}{l}\text { 3. I participate less than I used to in other fun activities } \\
\text { because of the time I spend watching porn. }\end{array}$ & $\begin{array}{c}2.66 \\
(1.76)\end{array}$ & $\begin{array}{c}28 \\
(34.1 \%)\end{array}$ & $\begin{array}{c}19 \\
(23.2 \%)\end{array}$ & $\begin{array}{c}12 \\
(14.6 \%)\end{array}$ & $\begin{array}{c}11 \\
(13.4 \%)\end{array}$ & $\begin{array}{c}5 \\
(6.1 \%)\end{array}$ & $\begin{array}{c}2 \\
(2.4 \%)\end{array}$ & $\begin{array}{l}5 \\
(6.1 \%)\end{array}$ \\
\hline $\begin{array}{l}\text { 4. I feel that I had to watch more and more porn for } \\
\text { satisfaction. }\end{array}$ & $\begin{array}{c}3.76 \\
(1.64)\end{array}$ & $\begin{array}{l}5 \\
(6.1 \%)\end{array}$ & $\begin{array}{c}13 \\
(15.9 \%)\end{array}$ & $\begin{array}{c}22 \\
(26.8 \%)\end{array}$ & $\begin{array}{c}21 \\
(25.6 \%)\end{array}$ & $\begin{array}{c}7 \\
(8.55)\end{array}$ & $\begin{array}{c}6 \\
(7.3 \%)\end{array}$ & $\begin{array}{c}8 \\
(9.8 \%)\end{array}$ \\
\hline $\begin{array}{l}\text { 5. When I promise myself not to watch porn anymore, I } \\
\text { can only stop for a short time. }\end{array}$ & $\begin{array}{c}4.39 \\
(1.92)\end{array}$ & $\begin{array}{c}9 \\
(11.0 \%)\end{array}$ & $\begin{array}{c}6 \\
(7.3 \%)\end{array}$ & $\begin{array}{c}12 \\
(14.6 \%)\end{array}$ & $\begin{array}{c}13 \\
(15.9 \%)\end{array}$ & $\begin{array}{c}15 \\
(18.3 \%)\end{array}$ & $\begin{array}{c}13 \\
(15.9 \%)\end{array}$ & $\begin{array}{c}14 \\
(17.1 \%)\end{array}$ \\
\hline $\begin{array}{l}\text { 6. I become stressed when something prevents me from } \\
\text { watching porn. }\end{array}$ & $\begin{array}{c}2.72 \\
(1.75)\end{array}$ & $\begin{array}{c}28 \\
(34.1 \%)\end{array}$ & $\begin{array}{c}14 \\
(17.1 \%)\end{array}$ & $\begin{array}{c}17 \\
(20.7 \%)\end{array}$ & $\begin{array}{c}11 \\
(13.4 \%)\end{array}$ & $\begin{array}{c}5 \\
(6.1 \%)\end{array}$ & $\begin{array}{c}2 \\
(2.4 \%)\end{array}$ & $\begin{array}{c}5 \\
(6.1 \%)\end{array}$ \\
\hline
\end{tabular}

Note. $M=$ mean; $S D=$ standard deviation. 


\section{Table 7}

Non-Zero Level Endorsement of the Six Items of the Short Version of the Problematic Pornography Consumption Scale (PPCS-6-A) among Low-Risk Problematic Pornography Users and At-Risk Problematic Pornography Users

\begin{tabular}{lcc} 
Item endorsement & $\begin{array}{c}\text { Low-risk problematic pornography } \\
\text { users }(n=714 ; 89.7 \%)\end{array}$ & $\begin{array}{c}\text { At-risk problematic pornography } \\
\text { users }(n=82 ; 10.3 \%) \\
n(\%)\end{array}$ \\
\hline Six out of six items endorsed on a non-zero level & $11(1.5 \%)$ & $35(42.7 \%)$ \\
Five out of six items endorsed on a non-zero level & $24(3.4 \%)$ & $20(24.4 \%)$ \\
Four out of six items endorsed on a non-zero level & $60(8.4 \%)$ & $21(25.6 \%)$ \\
Three out of six items endorsed on a non-zero level & $94(13.2 \%)$ & $5(6.1 \%)$ \\
Two out of six items endorsed on a non-zero level & $141(19.7 \%)$ & $1(1.2 \%)$ \\
One out of six items endorsed on a non-zero level & $147(20.6 \%)$ & $0(0.0 \%)$ \\
No item endorsed on a non-zero level & $237(33.2 \%)$ & $0(0.0 \%)$ \\
\hline
\end{tabular}

Note. Non-zero level endorsement refers to choosing other than the "never" answer option for items. 


\section{Appendix A}

\section{Short Version of the Problematic Pornography Consumption Scale in Adolescents (PPCS-6-A) \\ English Version - Short Problematic Pornography Consumption Scale in Adolescents (PPCS-6-A)}

For the following questions, the term 'pornography' is used to refer to: intentionally looking at or listening to: (1) pictures or videos of nude individuals, (2) pictures or videos in which people are having sexual activities

Please think back to the past six months and indicate on the following 7-point scale how often or to what extent the statements apply to you. There is no right or wrong answer. Please indicate the answer that most applies to you.

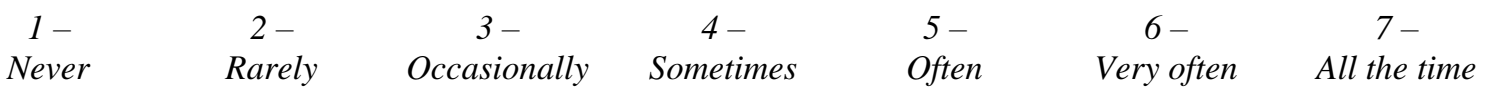

\begin{tabular}{llllllll}
\hline & 1 & 2 & 3 & 4 & 5 & 6 & 7 \\
\hline $\begin{array}{l}\text { 1. I feel that porn is a big part of my life. } \\
\text { 2. I relax by watching porn. }\end{array}$ & $\mathrm{O}$ & $\mathrm{O}$ & $\mathrm{O}$ & $\mathrm{O}$ & $\mathrm{O}$ & $\mathrm{O}$ \\
3. I participate less than I used to in other fun activities because of the time I & $\mathrm{O}$ & $\mathrm{O}$ & $\mathrm{O}$ & $\mathrm{O}$ & $\mathrm{O}$ & $\mathrm{O}$ \\
spend watching porn. & $\mathrm{O}$ & $\mathrm{O}$ & $\mathrm{O}$ & $\mathrm{O}$ & $\mathrm{O}$ & $\mathrm{O}$ & $\mathrm{O}$ \\
4. I feel that I had to watch more and more porn for satisfaction. & $\mathrm{O}$ & $\mathrm{O}$ & $\mathrm{O}$ & $\mathrm{O}$ & $\mathrm{O}$ & $\mathrm{O}$ & $\mathrm{O}$ \\
5. When I promise myself not to watch porn anymore, I can only stop for a short & $\mathrm{O}$ & $\mathrm{O}$ & $\mathrm{O}$ & $\mathrm{O}$ & $\mathrm{O}$ & $\mathrm{O}$ & $\mathrm{O}$ \\
time. & $\mathrm{O}$ & $\mathrm{O}$ & $\mathrm{O}$ & $\mathrm{O}$ & $\mathrm{O}$ & $\mathrm{O}$ & $\mathrm{O}$ \\
6. I become stressed when something prevents me from watching porn. & & &
\end{tabular}

Scoring: Add the scores of the items.

\section{French Version - Version abrégée de l'Échelle d'Utilisation Problématique de Pornographie pour les Adolescents (PPCS-6-A)}

Pour les questions suivantes, le terme " pornographie " est utilisé pour designer : regarder ou écouter intentionnellement (1) des images ou des vidéos d'individus nus et (2) des images ou des vidéos dans lesquels des personnes ont des activités sexuelles.

Repense aux six derniers mois et indique, sur l'échelle à 7 points suivante, à quelle fréquence ou dans quelle mesure ces énoncés s'appliquent à toi. Il n'y a pas de bonne ou de mauvaise réponse. Indique la réponse qui s'applique le plus à toi.
$1-$
$2-$
$3-$
4 -
$5-$
$6-$
$7-$
Jamais
Rarement
Occasionnellement
Parfois
Souvent
Très souvent
Tout le temps

\begin{tabular}{llllllll}
\hline & 1 & 2 & 3 & 4 & 5 & 6 & 7 \\
\hline $\begin{array}{l}\text { 1. Je sens que la porno occupe une grande place dans ma vie. } \\
\text { 2. Je me détends en regardant de la porno. }\end{array}$ & $\mathrm{O}$ & $\mathrm{O}$ & $\mathrm{O}$ & $\mathrm{O}$ & $\mathrm{O}$ & $\mathrm{O}$ \\
3. Je participe moins qu'avant à d'autres activités plaisantes à cause du temps que & $\mathrm{O}$ & $\mathrm{O}$ & $\mathrm{O}$ & $\mathrm{O}$ & $\mathrm{O}$ & $\mathrm{O}$ & $\mathrm{O}$ \\
je passe à regarder de la porno. & $\mathrm{O}$ & $\mathrm{O}$ & $\mathrm{O}$ & $\mathrm{O}$ & $\mathrm{O}$ & $\mathrm{O}$ & $\mathrm{O}$ \\
$\begin{array}{l}\text { 4. Je sens que je dois regarder de plus en plus de porno pour être satisfait(e). } \\
\text { 5. Quand je me promets de ne plus regarder de porno, je peux seulement arrêter } \\
\text { pour une courte période. }\end{array}$ & $\mathrm{O}$ & $\mathrm{O}$ & $\mathrm{O}$ & $\mathrm{O}$ & $\mathrm{O}$ & $\mathrm{O}$ & $\mathrm{O}$ \\
6. Je deviens stressé(e) quand quelque chose m'empêche de regarder de la porno. & $\mathrm{O}$ & $\mathrm{O}$ & $\mathrm{O}$ & $\mathrm{O}$ & $\mathrm{O}$ & $\mathrm{O}$ & $\mathrm{O}$ \\
\hline
\end{tabular}

Cotation: Additionner les scores des items. 


\section{SUPPLEMENTAL MATERIAL FOR:}

\section{Validity and Reliability of the Short Version of the Problematic Pornography Consumption Scale (PPCS-6-A) in Adolescents}

Beáta Bőthe, $\mathrm{PhD}^{1 *}$, Marie-Pier Vaillancourt-Morel, $\mathrm{PhD}^{2}$, Jacinthe Dion, $\mathrm{PhD}^{3}$, Aleksandar Štulhofer, $\mathrm{PhD}^{4}$, Sophie Bergeron, $\mathrm{PhD}^{1}$

${ }^{1}$ Département de Psychologie, Université de Montréal, Montréal, Canada

${ }^{2}$ Département de Psychologie, Université du Québec à Trois-Rivières, Trois-Rivières, Canada

${ }^{3}$ Intersectoral Center for Sustainable Health, Université du Québec à Chicoutimi, Chicoutimi, Canada

${ }^{4}$ Department of Sociology, Faculty of Humanities and Social Sciences, University of Zagreb, Zagreb, Croatia

*Corresponding author

Beáta Bőthe, Ph.D., Department of Psychology, Université de Montréal, C.P. 6128, Succursale Centre-Ville, Montréal, QC, H3C 3J7, Canada

E-mail: beata.bothe@umontreal.ca; beabothe@gmail.com

Tel.: + 514-343-6111 ext. 37428 


\section{Table S1}

Associations between the Short Version of the Problematic Pornography Consumption Scale (PPCS-6-A) with Pornography Use and Sexuality-Related Variables in Boys and Girls

\begin{tabular}{|c|c|c|c|c|c|c|c|c|c|c|c|}
\hline & Range & $\begin{array}{c}\text { Boys' } \\
\text { Mean }(S D)\end{array}$ & $\begin{array}{c}\text { Girls' } \\
\text { Mean }(S D)\end{array}$ & 1. & 2. & 3. & 4. & 5. & 6. & 7. & 8. \\
\hline 1. Problematic pornography use & $6-42$ & $\begin{array}{l}11.39 \\
(5.57)\end{array}$ & $\begin{array}{c}8.54 \\
(4.45)\end{array}$ & - & $-.17 * *$ & $.47 * *$ & $.33 * *$ & $.18^{* *}$ & .09 & $.15^{*}$ & .14 \\
\hline $\begin{array}{l}\text { 2. Age at first pornography use } \\
\text { (in years) }\end{array}$ & $6-18$ & $\begin{array}{l}11.96 \\
(1.76)\end{array}$ & $\begin{array}{l}13.03 \\
(1.71)\end{array}$ & $-.22 * *$ & - & $-.30 * *$ & $-.20 * *$ & $-.16^{*}$ & -.11 & -.11 & -.12 \\
\hline $\begin{array}{l}\text { 3. Frequency of pornography } \\
\text { use in the past three months a }\end{array}$ & $0-7$ & $\begin{array}{c}4.29 \\
(1.63)\end{array}$ & $\begin{array}{c}2.14 \\
(1.75)\end{array}$ & $.40 * *$ & $-.27 * *$ & - & $.65^{* *}$ & $.20 * *$ & $.18 * *$ & $.25 * *$ & $.23 * *$ \\
\hline $\begin{array}{l}\text { 4. Frequency of masturbation in } \\
\text { the past three months }{ }^{b}\end{array}$ & $1-8$ & $\begin{array}{c}5.32 \\
(2.08)\end{array}$ & $\begin{array}{c}2.96 \\
(2.19)\end{array}$ & $.23 * *$ & $-.22 * *$ & $.66^{* *}$ & - & $.18 * *$ & $.28 * *$ & $.25^{* *}$ & .08 \\
\hline 5. Sexual thoughts & $1-7$ & $\begin{array}{c}4.87 \\
(1.72)\end{array}$ & $\begin{array}{c}4.62 \\
(1.82)\end{array}$ & $.26 * *$ & $-.25 * *$ & $.29 * *$ & $.33 * *$ & - & $.54 * *$ & $.38 * *$ & .06 \\
\hline 6. Sexual drive & $1-6$ & $\begin{array}{c}4.25 \\
(0.85)\end{array}$ & $\begin{array}{c}4.10 \\
(0.87)\end{array}$ & $.25 * *$ & $-.24 * *$ & $.30 * *$ & $.32 * *$ & $.57 * *$ & - & $.49 * *$ & .03 \\
\hline 7. Sexual arousal & $1-6$ & $\begin{array}{c}4.18 \\
(0.79)\end{array}$ & $\begin{array}{c}4.08 \\
(0.86)\end{array}$ & $.20 * *$ & $-.20 * *$ & $.24 * *$ & $.24 * *$ & $.41 * *$ & $.43 * *$ & - & -.07 \\
\hline 8. Sexual distress ${ }^{c}$ & $0-4$ & $\begin{array}{c}0.60 \\
(0.66) \\
\end{array}$ & $\begin{array}{c}0.86 \\
(0.78) \\
\end{array}$ & $.26 * *$ & $-.14 *$ & $.20 * *$ & $.14 *$ & $.13 *$ & .09 & .02 & - \\
\hline
\end{tabular}

Note. $S D=$ standard deviation. Correlations presented below the diagonal represent the correlations for boys, correlations presented above the diagonal represent the correlations for girls.

${ }^{\mathrm{a}} 0=$ never, $1=$ less than 1 time per month, $2=1$ time per month, $3=2-3$ times per month, $4=1$ time per month, $5=$ many times per week, $6=1$ time per day, and $7=$ many times per day; ${ }^{b} 1=$ not once in the past three months; $2=$ less than once a month; $3=$ once a month; $4=$ two to three times a month; $5=$ once a week; $6=$ several times a week; $7=$ once a day; $8=$ more than once a day; ${ }^{\mathrm{c}}$ Only sexually active adolescents completed the Sexual Distress Scale $(n=430)$.

$* p<.05 ; * * p<.01$. 


\section{Table S2}

Associations between the Short Version of the Problematic Pornography Consumption Scale (PPCS-6-A) with Pornography Use and Sexuality-Related Variables in Heterosexual and Sexual Minority Adolescents

\begin{tabular}{|c|c|c|c|c|c|c|c|c|c|c|c|}
\hline & Range & $\begin{array}{l}\text { H Adolescents' } \\
\text { Mean }(S D)\end{array}$ & $\begin{array}{l}\text { SM Adolescents' } \\
\text { Mean }(S D)\end{array}$ & 1. & 2. & 3. & 4. & 5. & 6. & 7. & 8. \\
\hline 1. Problematic pornography use & $6-42$ & $\begin{array}{l}10.50 \\
(5.37)\end{array}$ & $\begin{array}{c}9.75 \\
(5.39)\end{array}$ & - & $-.25 * *$ & $.52 * *$ & $.35 * *$ & $.22 *$ & $.27 * *$ & $.37 * *$ & -.09 \\
\hline $\begin{array}{l}\text { 2. Age at first pornography use } \\
\text { (in years) }\end{array}$ & $6-18$ & $\begin{array}{l}12.30 \\
(1.83)\end{array}$ & $\begin{array}{l}12.57 \\
(1.65)\end{array}$ & $-.26 * *$ & - & $-.46 * *$ & $-.32 * *$ & -.16 & -.15 & -.13 & -.15 \\
\hline $\begin{array}{l}\text { 3. Frequency of pornography } \\
\text { use in the past three months a }\end{array}$ & $0-7$ & $\begin{array}{l}3.59 \\
(1.96)\end{array}$ & $\begin{array}{c}3.23 \\
(1.93)\end{array}$ & $.47 * *$ & $-.36 * *$ & - & $.64 * *$ & .19 & $.28 * *$ & $.24^{*}$ & .16 \\
\hline $\begin{array}{l}\text { 4. Frequency of masturbation in } \\
\text { the past three months }{ }^{b}\end{array}$ & $1-8$ & $\begin{array}{l}4.23 \\
(2.43)\end{array}$ & $\begin{array}{l}4.01 \\
(2.37)\end{array}$ & $.33 * *$ & $-.29 * *$ & $.73 * *$ & - & $.36^{* *}$ & $.43 * *$ & $.47 * *$ & .16 \\
\hline 5. Sexual thoughts & $1-7$ & $\begin{array}{l}4.95 \\
(1.66)\end{array}$ & $\begin{array}{c}4.69 \\
(1.87)\end{array}$ & $.23 * *$ & $-.22 * *$ & $.23 * *$ & $.23 * *$ & - & $.50 * *$ & $.43 * *$ & .09 \\
\hline 6. Sexual drive & $1-6$ & $\begin{array}{c}4.22 \\
(0.85)\end{array}$ & $\begin{array}{c}4.07 \\
(0.86)\end{array}$ & $.21 * *$ & $-.20 * *$ & $.25^{* *}$ & $.28 * *$ & $.57 * *$ & - & $.49 * *$ & .08 \\
\hline 7. Sexual arousal & $1-6$ & $\begin{array}{c}4.16 \\
(0.81)\end{array}$ & $\begin{array}{c}4.05 \\
(0.91)\end{array}$ & $.16^{* *}$ & $-.18 * *$ & $.24 * *$ & $.20 * *$ & $.39 * *$ & $.45^{* *}$ & - & -.10 \\
\hline 8. Sexual distress ${ }^{c}$ & $0-4$ & $\begin{array}{c}0.65 \\
(0.69) \\
\end{array}$ & $\begin{array}{c}1.03 \\
(0.86) \\
\end{array}$ & $.23 * *$ & -.06 & .08 & .02 & $.12 *$ & .05 & .03 & - \\
\hline
\end{tabular}

Note. $\mathrm{H}=$ heterosexual; $\mathrm{SM}=$ sexual minority; $S D$ = standard deviation. Correlations presented below the diagonal represent the correlations for heterosexual adolescents, correlations presented above the diagonal represent the correlations for sexual minority adolescents.

${ }^{\mathrm{a}} 0=$ never, $1=$ less than 1 time per month, $2=1$ time per month, $3=2-3$ times per month, $4=1$ time per month, $5=$ many times per week, $6=1$ time per day, and $7=$ many times per day; ${ }^{b} 1=$ not once in the past three months; $2=$ less than once a month; $3=$ once a month; 4 = two to three times a month; $5=$ once a week; $6=$ several times a week; $7=$ once a day; $8=$ more than once a day; ${ }^{\mathrm{c}}$ Only sexually active adolescents completed the Sexual Distress Scale $(n=430)$.

$* p<.05 ; * * p<.01$. 


\section{Figure S1}

Visualization of the Latent Classes Based on the Items of the Short Version of the Problematic Pornography Consumption Scale in Adolescents (PPCS-6-A)

\section{5}

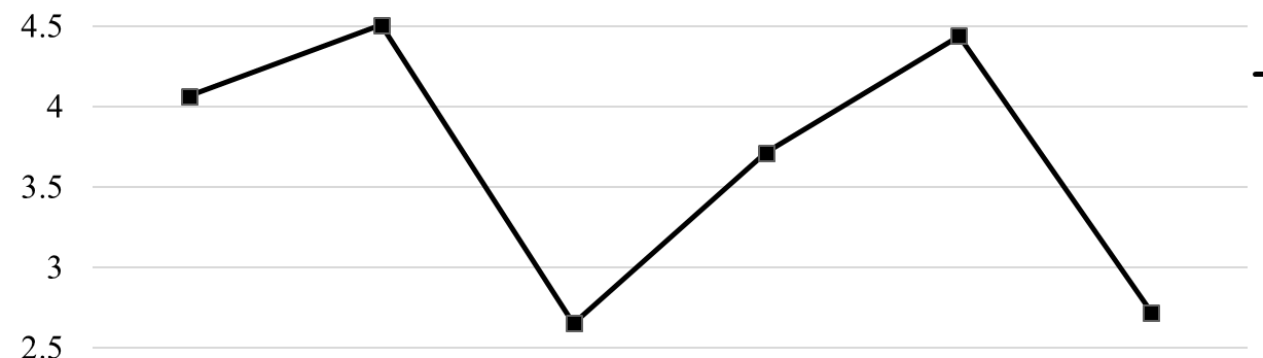

-m-At-risk problematic pornography users $(\mathrm{n}=82 ; 10.3 \%)$

\section{5}

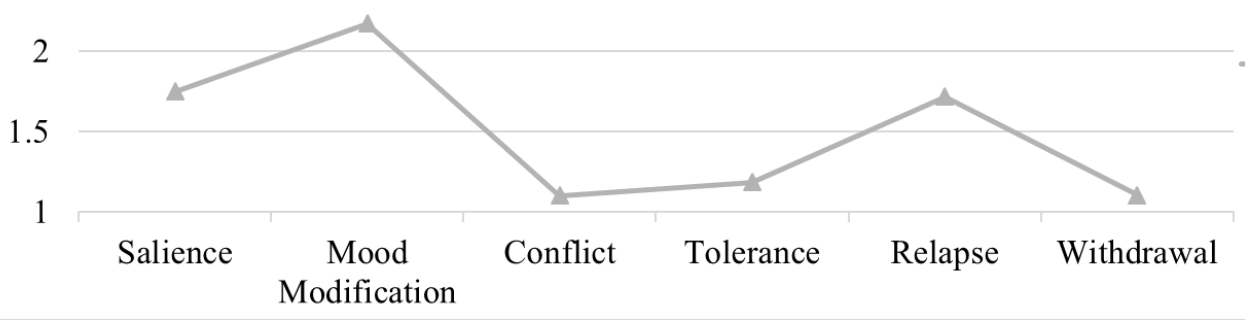

- Low-risk problematic pornography users $(\mathrm{n}=714 ; 89.7 \%)$ 